\title{
Implementation of a new urban energy budget scheme in the MetUM. Part I: Description and idealized simulations
}

Article

Published Version

Porson, A., Clark, P. A., Harman, I. N., Best, M. J. and Belcher, S. (2010) Implementation of a new urban energy budget scheme in the MetUM. Part I: Description and idealized simulations. Quarterly Journal of the Royal Meteorological Society, 136 (651). pp. 1514-1529. ISSN 1477-870X doi: https://doi.org/10.1002/qj.668 Available at https://centaur.reading.ac.uk/26983/

It is advisable to refer to the publisher's version if you intend to cite from the work. See Guidance on citing.

Published version at: http://dx.doi.org/10.1002/aj.668

To link to this article DOI: http://dx.doi.org/10.1002/qj.668

Publisher: Royal Meteorological Society

All outputs in CentAUR are protected by Intellectual Property Rights law, including copyright law. Copyright and IPR is retained by the creators or other copyright holders. Terms and conditions for use of this material are defined in the End User Agreement. 


\section{CentAUR}

Central Archive at the University of Reading

Reading's research outputs online 


\title{
RMetS
}

\section{Implementation of a new urban energy budget scheme in the MetUM. Part I: Description and idealized simulations}

\author{
A. Porson ${ }^{\mathrm{a} \star}$, P. A. Clark ${ }^{\mathrm{b} \dagger}$, I. N. Harman ${ }^{\mathrm{c}}$, M. J. Best $\mathrm{d}^{\mathrm{d} \dagger}$ and S. E. Belcher ${ }^{\mathrm{a}}$ \\ ${ }^{a}$ Department of Meteorology, University of Reading, $U K$ \\ ${ }^{\mathrm{b}}$ Joint Centre for Mesoscale Meteorology, Met Office, Reading, UK \\ ${ }^{\mathrm{C}}$ CSIRO Marine and Atmospheric Research, Canberra, Australia \\ d Joint Centre for Hydrometeorological Research, Met Office, Wallingford, UK \\ ${ }^{\star}$ Correspondence to: A. Porson, Met Office, FitzRoy Road, Exeter EX1 3PB, UK. \\ E-mail: aurore.porson@metoffice.gov.uk
}

$\dagger$ The contributions of P. A. Clark and M. J. Best were written in the course of their employment at the Met Office, UK, and are published with the permission of the Controller of HMSO and the Queen's Printer for Scotland.

This paper describes the formulation of a new urban scheme, MORUSES (Met Office-Reading Urban Surface Exchange Scheme) for use in the Met Office Unified Model. The implementation of the new scheme ensures that (1) the new scheme offers more flexibility in the parametrization of the building properties, and hence provides a more realistic representation of the fluxes; (2) the bulk outputs are in satisfactory agreement with previous observational studies; and (3) the impact of the new scheme on the energy balance fluxes is similar to the impact of the current urban scheme when set up to mimic it. As well as having a better physical basis, MORUSES also gains in flexibility in applications and adaptations to different urban materials as well as urban planning. The new scheme represents the urban area as a composition of two tiles, a canyon and a roof, using a simple 2D geometry. Sensitivity analysis to canyon geometry and thickness of the roof canopy emphasizes the gain in flexibility captured by the new scheme. Copyright (c) 2010 Royal Meteorological Society and Crown Copyright.

Key Words: $\quad$ urban parametrization; energy balance for canyon and roof; surface fluxes; NWP

Received 19 December 2008; Revised 15 February 2010; Accepted 8 May 2010; Published online in Wiley Online Library 27 August 2010

Citation: Porson A, Clark PA, Harman IN, Best MJ, Belcher SE. 2010. Implementation of a new urban energy budget scheme in the MetUM. Part I: Description and idealized simulations. Q. J. R. Meteorol. Soc. 136: 1514-1529. DOI:10.1002/qj.668

\section{Introduction}

Large populations live in urban areas, and more than $60 \%$ of the world's population is projected to reside within cities in the coming decades. This motivates us to understand and predict urban impacts on local climates. In this paper, we propose a new urban surface scheme, MORUSES (Met Office-Reading Urban Surface Exchange Scheme), and implement it into the Met Office Unified Model (MetUM). To serve this purpose, the new urban surface scheme is aimed at improving our understanding of the impact of urban areas within the communities of weather forecasting and regional climate modelling.
Numerical weather prediction (NWP) or regional climate modelling applications place constraints on the formulation of an urban surface scheme. On the one hand, the increase in resolution in these models means that urban areas are now resolved (being larger than a few gridboxes), but, on the other hand, the resolution remains too coarse to resolve the flow around individual buildings. Therefore, the effects of the buildings need to be parametrized. The parametrization ideally needs to be based on measurable properties of the buildings because it is neither desirable nor feasible to tune a model separately for each city, and even where fine local tuning is feasible, a good starting point should ideally be based on physically meaningful inputs. One way to address 
these constraints is to represent the city by generic building types. The most commonly used generic building type is a two-dimensional (2D) representation of a series of street canyons and roofs, first introduced by Nunez and Oke (1977) and now applied widely in the urban community (Masson, 2000; Kusaka et al., 2001; Martilli et al., 2002; Dupont and Mestayer, 2006; Harman and Belcher, 2006; Lee and Park, 2008). More information on these schemes can be found in the international urban projects of COST 715 (Fisher et al., 2006), FUMAPEX or COST 728 (Baklanov et al., 2006, 2008) and the intercomparison model exercise led by Grimmond et al. (2010). The scheme developed here will follow a 2D approach.

Additionally, NWP also requires a faithful representation of the energy fluxes from the surface, which provide the driving forcing to the atmosphere. The building canopy of urban areas has a finite depth so that the fluxes are delivered to the atmosphere over a finite depth, which is what multi-level urban models do. However, it is the overall flux that drives the large-scale atmospheric motions and so the urban canopy here can be represented as a single-layer model. Models that represent the urban canopy with multiple levels might be necessary for air pollution and dispersion applications (Hamdi and Masson, 2008; Baklanov et al., 2006), but this is not the main focus here. At the UK Met Office, the Nuclear Accident Modelling Exercise (NAME) model (Jones et al., 2006) post-processes model outputs from the MetUM for such applications, and future work may focus on improving the coupling between the MetUM and the NAME models over urban areas.

There remains the question of the number of separate active thermodynamic surfaces that are needed to represent the idealized geometry. Porson et al. (2009) showed that a two-facet (roof and canyon) representation is as accurate as a four-facet (roof, two walls and street) model using idealized obervations as well as observations of surface fluxes. Following these arguments, the new scheme, MORUSES, will adopt a two-facet formulation.

A last aspect in developing parametrizations for use in weather forecasting or regional climate modelling is their computational cost. Practical models require parameterizations to be as simple as possible to minimize the costs of maintaining and testing the code and the number of external parameters that must be supplied to run (Best, 2006).

To summarize, the urban surface scheme proposed here consists of two separate surfaces, one street and one roof. The physics of the parametrization relies on the simplification of a four-facet single-layer model (Harman et al., 2004a, b; Harman and Belcher, 2006). In particular, radiative exchange within the canyon is formulated with an effective albedo and an effective emissivity (Harman et al., 2004a). Heat transfer relies on the formulation of effective roughness lengths for momentum and for heat (Harman et al., 2004b). Storage of heat within the urban canopy (buildings) and the heat transfer to the deep soil are parametrized in order to represent the high thermal capacity of the urban surface. All these processes are dependent on town morphology.

Specific questions are:

1. Does the new scheme produce values of the bulk parameters consistent with previous measurements and models? The Best urban surface scheme currently implemented in the UM uses bulk parameter values that are not measurable directly. However MORUSES takes parameter values that are measurable from the urban fabric and geometry. This question is addressed here for three variables: the albedo, the roughness length for heat and the heat capacity or thermal inertia. Albedo values for cities are observed to be less than crops or grass (Jin et al., 2005), due to multireflection within the canyon (Aida and Gotoh, 1982). In the current UM scheme, Best (2005) adopts a value of 0.18 to represent the whole urban canopy. However, urban facet albedo values can sometimes vary from 0.08 up to 0.5 (Masson et al. 2002), so how do these facet values aggregate? Additionally, since the albedo itself depends on geometry, its value is best calculated with a geometry-dependent formulation. Secondly, Best et al. (2006) have shown that the roughness length for heat should decrease by six orders of magnitude, from $10^{-1}$ times the roughness length for momentum (which is of $\mathrm{O}(1 \mathrm{~m})$ ), in order to obtain a good agreement between the model and observations of surface fluxes. Despite a few attempts to approximate this parameter (Lemonsu et al., 2004; Kanda et al., 2005), a comprehensive physical model is lacking. Thirdly, in Best (2005), the thermal inertia of the urban surface is represented by a relatively high value of the heat capacity. Here, we propose a formulation for thermal inertia that involves volumetric heat capacity and thickness values from urban material properties (brick, tiles and asphalt).

2. How consistent is the new scheme with the current scheme? The current scheme has been extensively tuned to give reasonable results in a (small) number of situations. The new scheme is introduced in order to represent more physical processes as well as to provide more flexibility in the parametrization of the building properties, but it is worthwhile checking that the new scheme's energy balance matches, to a certain extent, qualitatively and quantitatively, the energy balance of the current scheme when it is set up for conditions similar to those for which the current scheme was tuned. The two schemes cannot be rigorously compared because of the dependence on geometry (which is included in the new scheme, but not included in the current scheme). The sensitivity to geometry will be partly investigated in addressing question 1 about the bulk values of the parameters and their dependence on geometry, but the direct impact on the energy balance fluxes needs to be researched further, which brings the following questions.

3. The new scheme consists of a series of parametrizations of urban processes. What is the sensitivity of the energy balance to these urban processes? To evaluate the impact of the new scheme on the energy balance of the MetUM, it is important to evaluate the sensitivity of the energy balance to each urban process implemented with the new scheme. To achieve this goal, an ideal method would be to perturb the energy balance of a simple flat surface by adding each urban process separately, and evaluate the deviations in the surface fluxes.

4. Considering the fact that the new scheme depends on urban geometry and the current scheme does not, how do the two schemes compare and what do we 
learn about the current scheme's performance versus the sensitivity of the new scheme to city geometry?

5. What is the sensivity of the new scheme to roof properties? Following Harman and Belcher (2006), the accuracy of roof properties is crucial to control the coupling between the urban surface and the atmosphere. Porson et al. (2009) have shown that urban canopy models are best represented with two surfaces and that one-surface urban canopy models could fail to capture properly the mixing of atmospheric fluxes from the canyon and the roof surfaces. In the first paper of this research, our goal is to estimate the sensitivity of the surface fluxes to a change in roof properties due, for example, to insulation.

These questions will be addressed in Part I of this work in three main sections: (2) model description and development, (3) idealized simulations with the MetUM, and (4) conclusions. In Part II (Porson et al., 2010), the new scheme MORUSES will be further evaluated against observations and model outputs from another urban surface scheme for which the urban canopy is resolved using a temperature diffusion equation over multiple substrate layers.

\section{Model formulation}

\subsection{Description of the MetUM surface scheme and the Best scheme}

The MetUM surface exchange scheme has nine surfaces: five vegetation and four non-vegetated surfaces including the urban surface. Essery et al. (2003) introduced subgridscale heterogeneity within the MetUM using a tile scheme: a particular grid box is then described by the percentage land use of each of these nine tiles. The surface energy balance is then calculated separately for each surface tile and the results combined to give the grid box average using the blending height concept. As a consequence, each tile produces its own surface fluxes, its own vertical gradients of prognostic atmospheric variables (wind, temperature and humidity) between the surface and an atmospheric level called 'the blending height'. Above the blending height, these vertical gradients merge and the grid box average flux provides the lower boundary condition to the first atmospheric model level and the boundary-layer scheme (Lock et al., 2000). The blending height level should be derived iteratively, but, in practice in the MetUM, it coincides with the first atmospheric level even in models with relatively high vertical resolution. The blending height is a height scale, and not a rigorously defined height. However, the concept of blending height perhaps becomes stretched over urban areas where the length-scale of heterogeneity becomes less than 100-200 m (Mason, 1988; Clark et al., 2008) and further work may be needed to improve this formulation. As a consequence of this blending, the tiles are not completely independent of each other, since all of them are bounded by the same atmospheric conditions. Note that the soil is not tiled, so a total ground heat flux has to be calculated by aggregation of all tiles. More information on tile schemes and their coupling to the boundary layer can be found in Best et al. (2004).

Copyright (C) 2010 Royal Meteorological Society and Crown Copyright.
Depending on the land cover type it represents, each tile follows a surface energy balance equation as:

$$
C \frac{\mathrm{d} T_{*}}{\mathrm{~d} t}=R_{\mathrm{N}}-Q_{\mathrm{H}}-Q_{\mathrm{E}}-G,
$$

with $T_{*}$ the surface (or canopy) temperature, $C$ the areal heat capacity $\left(\mathrm{J} \mathrm{K}^{-1} \mathrm{~m}^{-2}\right), R_{\mathrm{N}}$ the net radiation $\left(\mathrm{W} \mathrm{m}^{-2}\right), Q_{\mathrm{H}}$ the sensible heat flux $\left(\mathrm{W} \mathrm{m}^{-2}\right), Q_{\mathrm{E}}$ the latent heat flux $\left(\mathrm{W} \mathrm{m}^{-2}\right)$ and $G$ the ground heat flux $\left(\mathrm{W} \mathrm{m}^{-2}\right.$ ) (Cox et al., 1999; Essery et al., 2001; Essery et al., 2003). Note that the $C \mathrm{~d} T_{*} / \mathrm{d} t$ term remains if the surface has a certain thickness, and then forms a canopy. Note that there is no anthropogenic heat flux in Eq. (1); work is currently being undertaken to evaluate anthropogenic heat sources over urban areas in the UK. The net radiation flux $R_{\mathrm{N}}$ is taken as the sum of the net solar radiation $R_{\mathrm{S}}$ and net long-wave radiation $R_{\mathrm{L}}$. The sensible heat flux $Q_{\mathrm{H}}$ and latent heat flux $Q_{\mathrm{E}}$ are formulated as:

$$
\begin{gathered}
Q_{\mathrm{H}}=\rho c_{p} f_{\mathrm{H}} C_{\mathrm{H}} U(1) \Delta T, \\
Q_{\mathrm{E}}=\psi \rho c_{p} f_{\mathrm{H}} C_{\mathrm{H}} U(1) \Delta q,
\end{gathered}
$$

with $\psi$ a factor depending on aerodynamical resistance, soil and vegetation resistance to evaporation (Essery et al., 2003), $\Delta T$ and $\Delta q$ respectively the temperature and humidity differences between the surface and the first atmospheric level, $C_{\mathrm{H}}$ the heat transfer coefficient (defined later in section 2.4), $f_{\mathrm{H}}$ a stability function (Essery et al., 2001; McCabe and Brown, 2007) and $U(1)$ the wind speed at the first atmospheric level. The ground heat flux $G$ is usually expressed as a linear combination of radiative exchange and heat conduction, depending on a radiative fraction $f_{\text {rad }}$ :

$$
G=f_{\mathrm{rad}}\left(\sigma T_{*}^{4}-\sigma T_{\mathrm{soil}}^{4}\right)+\left(1-f_{\mathrm{rad}}\right) \frac{2 \lambda}{\Delta z}\left(T_{*}-T_{\text {soil }}\right),
$$

with $f_{\text {rad }}$ dependent on the land-cover type, $T_{\text {soil }}$ the surface soil layer temperature, $\lambda$ the thermal conductivity and $\Delta z$ the thickness of the top soil layer. The aggregation of the ground heat flux $G$ from all tiles, as a function of fractional cover type, represents the top boundary condition to a soil temperature diffusion equation:

$$
G_{\text {soil }}=\lambda_{\text {soil }} \frac{\partial T_{\text {soil }}}{\partial z}
$$

with $\lambda_{\text {soil }}$ the soil thermal conductivity. The soil temperature is also controlled by advective moisture fluxes (Essery et al., 2001). Although each tile has its own surface energy balance, one tile can influence another through its individual impact on the soil or on the atmosphere.

\subsection{The current scheme (Best scheme) and the new urban scheme (MORUSES)}

A description of the two urban schemes follows here and a schematic of how the two schemes are coupled to the atmosphere and underlying soil is illustrated in Figure 1. In the current urban scheme, Best (2005) implemented a weak radiative coupling between the urban canopy and the underlying soil by assuming a radiative fraction $f_{\text {rad }}$ equal to 1, so:

$$
G=\left(\sigma T_{\text {urban }}^{4}-\sigma T_{\text {soil }}^{4}\right)
$$




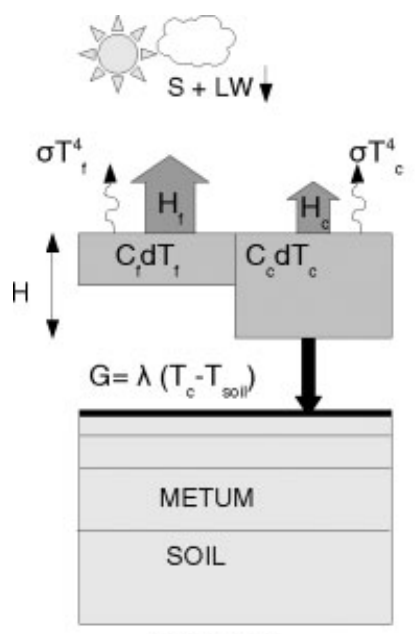

MORUSES
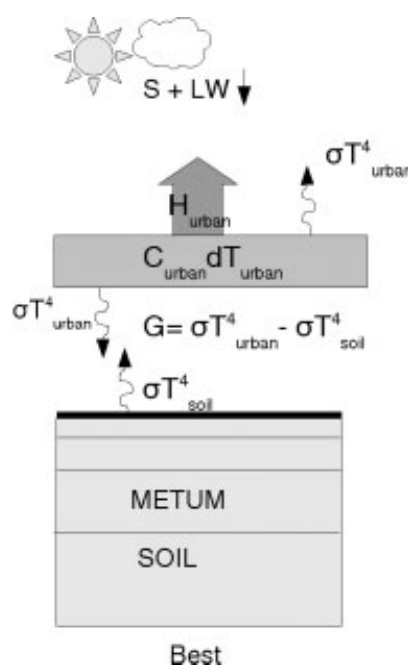

Figure 1. Schematics of MORUSES and the Best scheme.

with $T_{\text {urban }}=T_{*}$, the urban canopy temperature. The link between the areal heat capacity and the depth scale of the canopy is fully detailed in section 2.5. For typical volumetric material properties, the urban canopy is made effectively thick compared with the depth scale by using a high magnitude of the areal heat capacity (which Best chooses to be $0.28 \mathrm{~J} \mathrm{~K}^{-1} \mathrm{~m}^{-2}$ ). The combination of the weak coupling to the underlying soil and the 'thick-canopy' areal heat capacity allows the urban surface to store a large fraction of the energy provided by the net radiation within the urban substrate. As a result, the urban canopy is characterized by a large thermal inertia. Additionally, in this scheme, the capacity of the urban canopy to hold water is minimal $\left(0.5 \mathrm{~kg} \mathrm{~m}^{-2}\right)$ and drainage of water is favoured over surface infiltration. This limits the evaporation to periods directly after precipitation and so the urban canopy is therefore often equivalent to a dry, one-layer block with a high heat capacity. Because urban cover always contains yet finer scales of vegetation (i.e. gardens, irrigation), the MetUM, using Centre for Ecology and Hydrology (CEH) data for land cover, assumes 100\% cover fraction for continuous urban development, but 50\% for suburban areas with $40 \%$ of C3 grass and 10\% of bare soil. Overall, due to the large high thermal inertia, the Best scheme has led to significant improvements in the bias and r.m.s. errors of urban temperatures from the Met Office's operational $12 \mathrm{~km}$ resolution forecast (Best, 2005).

The new urban scheme introduced here follows a simplified 2D repeating geometry following Oke (1987) and many others such as Masson (2000) and Martilli et al. (2002). A schematic of this simplified 2D geometry is illustrated in Figure 2. Because most European cities show random street orientation, no specific canyon orientation is chosen and the new scheme is implemented with averaging over canyon orientations. If $W$ represents the road width, $R$ the combined length for the road and roof, and $H$ the building height, it is possible to express the planar and frontal indices $\lambda_{\text {plan }}$ and $\lambda_{\text {front }}$ as a function of the ratios $H / W$ and $W / R$ as:

$$
\begin{aligned}
& \lambda_{\text {plan }}=1-\frac{W}{R}, \\
& \lambda_{\text {front }}=\frac{2}{\pi} \frac{H}{W} \frac{W}{R},
\end{aligned}
$$

where the $2 / \pi$ comes from orientational averaging. This geometry will be represented by two facets, a canyon and a

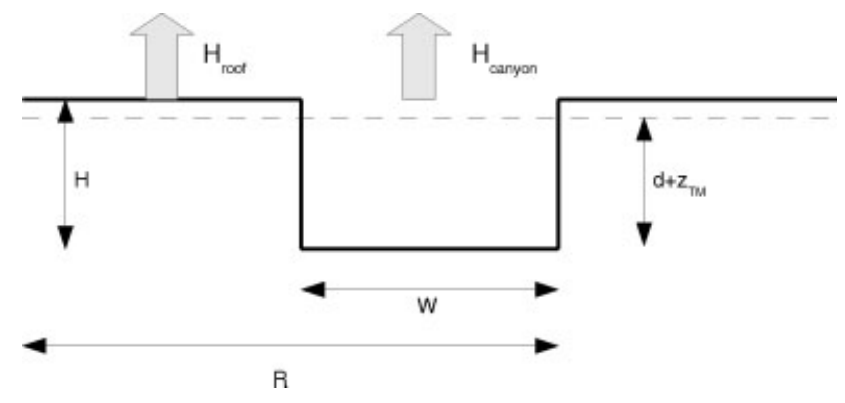

Figure 2. Schematics of the simplified 2D geometry of the urban canopy. The height $d+z_{\mathrm{TM}}$ represents the origin of the vertical coordinate system in the model.

roof. Compared to a 1-facet approach, a 2-facet approach is justified by the large differences in the surface energy balance fluxes between the canyon and the roof (Harman and Belcher, 2006), particularly for insulated roof material (Porson et al., 2009). Because of these differences in the energy balance, the canyon and the roof have to be modelled as separate tiles within the MetUM. Following the subgridscale tile scheme from Essery et al. (2003), the canyon and the roof tiles have separate surface energy balance equations depending on their own parameters and characteristics. In the following subsections, we describe the characteristics of the canyon and roof tiles with respect to the energy balance terms. In total, four parametrized processes characterize the new urban scheme:

1. The exchange of short-wave radiation within the canyon (calculation of the net solar radiation for the canyon tile $R_{S}$ );

2. The exchange of long-wave radiation within the canyon (calculation of the net long-wave radiation for the canyon tile $R_{L}$ );

3. The transfer of sensible heat flux through a resistance network for the calculation of the sensible heat flux $Q_{\mathrm{H}}$;

4. The thermal inertia and coupling with the underlying soil for the residual terms of storage $C \mathrm{~d} T / \mathrm{d} t$ and ground heat flux $G$.

As the roof tile behaves as a flat surface for short-wave and long-wave flux densities, the following two subsections will focus only on describing the solar and long-wave budgets for the canyon tile. In the description of the facet parameters, we use systematically the subscripts ' $r$ ' for road, 'w' for wall, 'f for roof and ' $c$ ' for canyon.

\subsection{Exchange of radiation within the street canyon}

The method used here relies on Sparrow and Cess (1970) and Harman et al. (2004a,b). The canyon is conceived as an enclosed 2D box, which includes four facets (one road, two walls and the sky). As mentioned earlier, to avoid the use of a specific canyon orientation, we average over canyon orientations. With respect to the solar radiation, averaging over canyon orientations implies that the two walls will receive exactly the same amount of radiance. The two walls are then lumped together, which results in a closed box with three facets: the road, the two walls (lumped together) and the sky. The vectors described in the following mathematical development will have three components, each of these refer to the three facets as: 1 for road, 2 for walls, 3 for sky. 
Table I. Symbols for radiation parametrization of the canyon tile.

\begin{tabular}{ll}
\hline Symbol & Definition \\
\hline$\alpha_{\mathrm{r}}$ & Road albedo \\
$\alpha_{\mathrm{W}}$ & Wall albedo \\
$\varepsilon_{\mathrm{r}}$ & Road emissivity \\
$\varepsilon_{\mathrm{W}}$ & Wall emissivity \\
$\mathbf{B}$ & Outgoing exchange-diffuse radiation \\
$\Lambda$ & Incoming exchange-diffuse radiation \\
$\mathbf{Q}_{\mathrm{S}}$ & Net solar exchange-diffuse radiation \\
$\mathbf{R}_{\mathrm{S}}$ & Net solar radiation \\
$\mathbf{R}_{\mathrm{L}}$ & Net long-wave radiation \\
\hline
\end{tabular}

The exchange of radiation within the canyon is diffuse and so as not to confuse with the use of the word 'diffuse' that represents the diffuse/scattered radiation component of the sky, we will name it 'exchange-diffuse'. A list of the symbols used to represent the radiative variables is included in Table I.

To evaluate the bulk albedo and the bulk emissivity, in the following development we aim at parametrizing the net solar radiation and net long-wave radiation, respectively.

\subsubsection{Bulk albedo}

To obtain the net solar radiation for the canyon tile, we need to calculate the direct component of incoming solar radiation on each facet and the exchange-diffuse component between each facet. Consider first the derivation of the direct component. For an incident solar radiation density at the top of the canopy $S_{\text {incident }}\left(\mathrm{W} \mathrm{m}^{-2}\right)$, we define the matrix $\mathbf{S}^{\downarrow}$ as the direct incoming solar radiation density reaching the three facets and the matrix $S^{\downarrow \uparrow}$ the emitted (or reflected) solar radiation density from the three facets as:

$$
\begin{aligned}
\mathbf{S}^{\downarrow} & =\left[\begin{array}{c}
S_{\mathrm{r}}^{\downarrow} \\
S_{\mathrm{w}}^{\downarrow} \\
S_{\text {sky }}^{\downarrow}
\end{array}\right]=\left[\begin{array}{c}
\left(1-\chi_{\mathrm{f}}\right) \chi_{\mathrm{r}} \\
\left(1-\chi_{\mathrm{f}}\right) \chi_{\mathrm{w}} \\
1
\end{array}\right] S_{\text {incident }}, \\
\mathbf{S}^{\downarrow \uparrow} & =\left[\begin{array}{c}
S_{\mathrm{r}}^{\downarrow \uparrow} \\
S_{\mathrm{w}}^{\downarrow \uparrow} \\
S_{\text {sky }}^{\downarrow \uparrow}
\end{array}\right]=\left[\begin{array}{c}
\alpha_{\mathrm{r}}\left(1-\chi_{\mathrm{f}}\right) \chi_{\mathrm{r}} \\
\alpha_{\mathrm{w}}\left(1-\chi_{\mathrm{f}}\right) \chi_{\mathrm{w}} \\
\chi_{\mathrm{f}}
\end{array}\right] S_{\text {incident }},
\end{aligned}
$$

where $\chi_{\mathrm{f}}$ represents the fraction of $S_{\text {incident }}$ scattered by the sky (estimated to 0.3), $\chi_{\mathrm{r}}$ and $\chi_{\mathrm{w}}$ represent the shadowing factors defined in Masson (2000) (in his Eqs (13) and (14)), so that $\left(1-\chi_{\mathrm{f}}\right) \chi_{\mathrm{r}}$ and $\left(1-\chi_{\mathrm{f}}\right) \chi_{\mathrm{w}}$ represent the fractions of $S_{\text {incident }}$ reaching the road and the two walls respectively after sky diffusion and shadowing effects. The road albedo is $\alpha_{\mathrm{r}}$ and the wall albedo is $\alpha_{\mathrm{w}}$, so that $\alpha_{\mathrm{r}}\left(1-\chi_{\mathrm{f}}\right) \chi_{\mathrm{r}}$ and $\alpha_{\mathrm{w}}\left(1-\chi_{\mathrm{f}}\right) \chi_{\mathrm{w}}$ represent the fractions of $S_{\text {incident }}$ emitted from the road and the walls respectively. We now have the vector $\mathbf{S}^{\downarrow}$ that represents the direct incoming solar radiation density, and the vector $S^{\downarrow \uparrow}$ that represents the reflected part of the direct incoming solar radiation density. These reflected densities will now be used to evaluate the multireflections of solar radiation within the canyon, through a process of exchange of radiation between each pair of canyon facets. We name this process 'the exchange-diffuse radiation'.
Let us now consider how to compute the exchange-diffuse radiation. We define the net exchange-diffuse radiation density as $Q_{s} \times S_{\text {incident }}$, the incoming exchange-diffuse radiation density as $\Lambda \times S_{\text {incident }}$ and the outgoing exchangediffuse radiation density as $\mathbf{B} \times S_{\text {incident, }}$, with

$$
\mathbf{Q}_{\mathrm{s}}=\Lambda-\mathbf{B} \text {. }
$$

Note that $\mathbf{Q}_{\mathbf{s}}, \Lambda$ and $\mathbf{B}$ represent fractions of solar radiation density, and are therefore non-dimensional. Harman et al. (2004a,b) revisited the exchange-diffuse radiation method developed by Sparrow and Cess (1970). This method relates the incoming radiation density $\Lambda \times S_{\text {incident }}$ onto a facet $i$ to the outgoing radiation density $\mathbf{B} \times S_{\text {incident }}$ from a facing facet $j$, through a matrix of exchange coefficients $\mathbf{F}_{i j}$. By using the geometry of a 2D canyon box, Harman et al. (2004a,b) calculated the matrix of exchange coefficients $\mathbf{F}_{i j}$ for the cases of road, walls, and sky. Following their work, we formulate $\mathbf{B}, \Lambda$ and $\mathbf{Q}_{\mathrm{s}}$ as:

$$
\begin{aligned}
\Lambda_{i} & =\sum_{j} F_{i j} B_{j}, \quad i, j=1,2,3, \\
B_{i} & =\sum_{j} \Psi_{i j}\left(S_{j}^{\downarrow \uparrow} / S_{\text {incident }}\right),
\end{aligned}
$$

with $\left(\Psi_{i j}\right)^{-1}=\delta_{i j}-\alpha_{i} F_{i j}, \quad i, j=1,2,3$,

$$
Q_{S, i}=\Lambda_{i}-B_{i}, \quad i, j=1,2,3 .
$$

The net fraction $f_{S \downarrow}$ of direct incoming solar radiation $S_{\text {incident }}$ going into the canyon is the sum of the direct and the exchange-diffuse fractions, weighted by the canyon geometry:

$$
\begin{aligned}
f_{S \downarrow}= & {\left[\left(1-\chi_{\mathrm{f}}\right) \chi_{\mathrm{r}}+Q_{S, \mathrm{r}}\right] } \\
& +\frac{2 H}{W}\left[\left(1-\chi_{f}\right) \chi_{\mathrm{w}}+Q_{S, \mathrm{w}}\right] .
\end{aligned}
$$

The bulk albedo is $1-f_{S \downarrow}$ and the bulk net solar radiation for the canyon tile is $R_{S, \mathrm{c}}=\left(1-f_{S \downarrow}\right) S_{\text {incident }}$.

Figure 3 illustrates the dependence of the bulk albedo on zenith angle and on canyon geometry. Wall albedo $\alpha_{\mathrm{w}}$ is set to 0.5 and road albedo $\alpha_{\mathrm{r}}$ to 0.08 . Such values were used by Masson et al. (2002) to represent the asphalt road surface in Vancouver. The run was made for day 210 (end of July) and at $50^{\circ} \mathrm{N}$ (these conditions match the set-up of the following idealized simulations). For low values of $H / W$, there is a clear minimum of effective albedo with low zenith angles (maximum value of $S^{\downarrow}$ ). For high values of $H / W$, the variation with zenith angle is negligible. For $H / W$ varying from 0.1 to 1 , the minimum value of albedo increases. However, for $H / W$ larger than 1 , the minimum value decreases again, suggesting a significant contribution from the exchange-diffuse component.

Referring to Harman et al. (2004a,b), the derivation of the bulk albedo described here is the exact solution (no approximation in the number of multi-reflections is used), and, in this respect, is the closest representation of multireflection calculation to the Monte-Carlo methods (Aida and Gotoh, 1982; Kondo et al., 2001). Kondo et al. (2001) developed a 3D Monte-Carlo approach and showed that the bulk albedo decreases for increasing building heights, which is similar to the results in Figure 3 for H/W larger than 1. For $H / W$ smaller than 1 , the bulk albedo value is largely dominated by the very small road albedo $(0.08)$, in contrast 


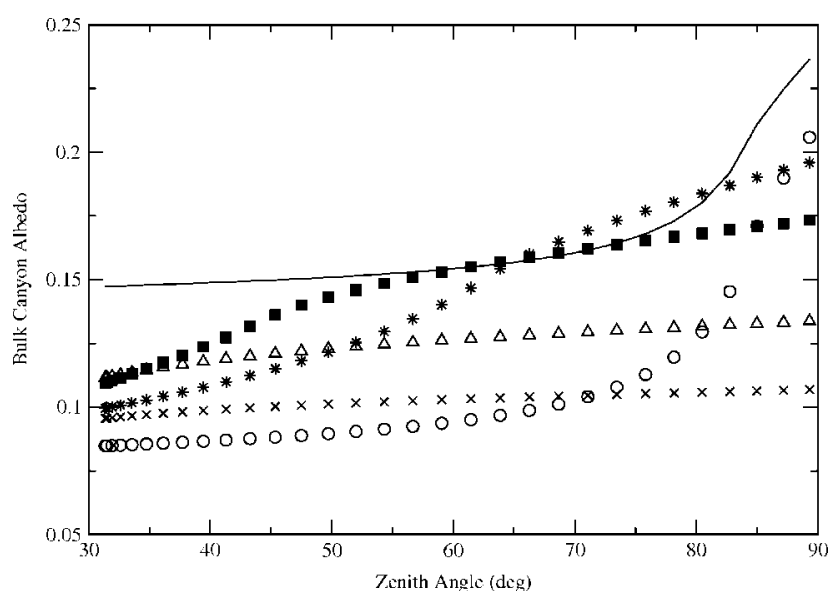

Figure 3. Model outputs of bulk albedo dependence as a function of zenith angle and height-to-width aspect ratio $(H / W)$, with $\alpha_{\mathrm{r}}=0.08$ Input parameters are defined in Table IV. The symbols denote $H / W$ values 0.1 (circles), 0.5 (stars), 1.0 (squares), 2.0 (triangles), and 3.0 (crosses). The solid line shows $H / W=0.1$ and $\alpha_{\mathrm{r}}=0.15$.

to the large wall albedo (0.50). To confirm this, the solid line in Figure 3 represents the bulk canyon albedo computed for $H / W$ of 0.1 and using a road albedo value of 0.15 instead of 0.08 . These results underline the difficulty in comparing such methods for heterogeneous surfaces. Aida and Gotoh (1982) used a 2D Monte-Carlo approach and obtained minimum bulk albedo values for intermediate zenith angles. Figure 3 shows increasing values of the bulk albedo for increasing zenith angles at small $H / W$, while for high $H / W$, the variation with zenith angle gets smoother. Alternately, Kondo et al. (2001) obtained very little variation when plotting albedo values against a time period between 1200 and 1900 local time, indicating that the albedo dependence on zenith angle is negligible in their study. The degree to which these models can be compared depends on the assumptions made in their inputs. For example, Aida and Gotoh (1982) assume that each photon has a $50 \%$ probability to be reflected istotropically or specularly. They show that the magnitude and variation of the bulk albedo are both sensitive to this probability value, and also to the choice of the reflectivity function.

Jin et al. (2005) used Earth Observation System observations from the Moderate Resolution Imaging Spectrometer to compute urban albedo values as a weighted average of spectral albedos. They found that the urban albedo values were largely controlled by the near-infrared (NIR) spectral band. They found an average albedo value between the visible and NIR bands of 0.15 . However, they note that this value depends not only on the wavelength but also on the fractions and types of urban surface represented, since urban materials such as asphalt have low albedos and emissivities. As mentioned previously, the very small road albedo values dominate the bulk albedo values for low $H / W$ ratios. Best (2005) uses a bulk albedo value for the urban tile of 0.18 . Since the bulk albedo value modelled by the new scheme depends on canyon geometry and on the parameters of the canyon facets, the new scheme offers more flexibility than the current scheme. For the inputs in albedo parameter values we used to produce Figure 3 (road albedo of 0.08 ), a bulk albedo of roughly 0.2 can only be achieved for low $H / W$ and high zenith angles. If another set of parameter values was chosen (for example a road albedo of 0.15 as represented by the solid line), a bulk albedo value

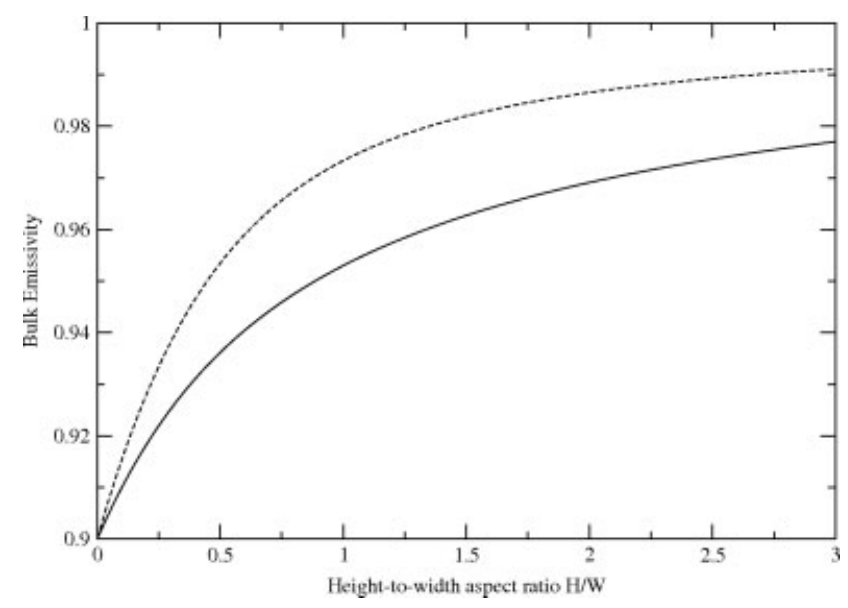

Figure 4. Model outputs of bulk emissivity as a function of $H / W$ for two sets of material emissivity: with $\varepsilon_{\mathrm{w}}=0.85$ and $\varepsilon_{\mathrm{r}}=0.90$ (solid line), and with $\varepsilon_{\mathrm{W}}=0.95$ and $\varepsilon_{\mathrm{r}}=0.90$ (dotted line).

of roughly 0.2 could also be reached for higher $\mathrm{H} / \mathrm{W}$ ratios. In the following idealized simulations, for similarity to the observational study of Masson et al. (2002), the road albedo will be fixed to 0.08 , so that the bulk albedo of the new scheme will be lower than the value of 0.18 of the current scheme, unless at small $H / W$.

\subsubsection{Bulk emissivity}

We define the emitted long-wave radiation density $\mathbf{L}^{\downarrow \uparrow}$ by each facet as:

$$
\mathbf{L}^{\downarrow \uparrow}=\left[\begin{array}{c}
L_{\mathrm{r}}^{\downarrow \uparrow} \\
L_{\mathrm{w}}^{\downarrow \uparrow} \\
L_{\text {sky }}^{\downarrow \uparrow}
\end{array}\right]=\left[\begin{array}{c}
\varepsilon_{\mathrm{r}} \sigma T_{\mathrm{c}}^{4} \\
\varepsilon_{\mathrm{w}} \sigma T_{\mathrm{c}}^{4} \\
L W^{\downarrow}
\end{array}\right],
$$

with $L W^{\downarrow}$ the downward long-wave radiation density, $\varepsilon_{\mathrm{r}}$ the road emissivity and $\varepsilon_{\mathrm{w}}$ the wall emissivity. Note that for the sky facet, we make the assumption that the sky emissivity $\varepsilon_{\text {sky }}$ is equal to 1 .

Following a similar procedure to the one leading to Eqs (12) and (13), we can derive the net long-wave radiation for the canyon tile $R_{L, \mathrm{c}}$ as:

$$
R_{L, \mathrm{c}}=\varepsilon L W^{\downarrow}-\varepsilon \sigma T_{\mathrm{c}}^{4}
$$

with $\varepsilon$ the canyon bulk emissivity. The details of this derivation are included in the appendix.

As shown in Figure 4 for two sets of material emissivity, the bulk emissivity values imply higher absorption and emission from the canyon tile $(H / W>0)$, than a flat surface. Note that Figure 4 is similar to Figure 4 in Harman et al. (2004a). While this parametrization aims at representing the impact of long-wave exchange within the canyon box, urban emissivities are usually measured to be lower than other land-cover surfaces (Jin et al., 2005). As for the albedo, the use of material with dark and impervious surfaces in urban areas lowers the material emissivity.

\subsection{Transfer of heat}

Heat transfer in the MetUM is parametrized in terms of heat transfer coefficients. To compute the heat transfer coefficients, the roughness length for momentum $z_{\mathrm{TM}}$ and 
the roughness length for heat $z_{\mathrm{TH}}$ need to be parametrized or estimated. In the Best scheme $z_{\mathrm{TM}}$ is set to $1 \mathrm{~m}$, and the ratio between $z_{\mathrm{TM}}$ and $z_{\mathrm{TH}}$ is set to $10^{-1}$ (as usually estimated for vegetation surfaces). Best et al. (2006) reevaluated this ratio to $10^{-7}$, in agreement with Voogt and Grimmond (2000) and Kanda et al. (2005). The latter value is used with the Best scheme. Here, in MORUSES, we compute the value of $z_{\mathrm{TH}}$. This drop in the magnitude of $z_{\mathrm{TH}}$ is explained by the difference in the physical meaning of $u_{*}$ and the sensible heat flux $Q_{\mathrm{H}}$ within the numerical model. On the one hand, urban areas exert a drag on the boundary layer through both a pressure drag force and through skin friction. Compared to a flat surface, for a given wind speed, this acts to increase the drag on the boundary layer. In these conditions, $u_{*}$ and $z_{\mathrm{TM}}$ both increase. On the other hand, heat and other scalars are exchanged solely through molecular diffusion at the surface. Barlow et al. (2004) and Harman et al. (2004a,b) show that, for the same surface to boundary layer scalar concentration difference, the total exchange for an urban-like surface is approximately the same as for a flat surface. In surface-layer theory, the sensible heat flux $Q_{\mathrm{H}}$ is equal to $\rho C_{p} u_{*} \theta_{*}$, where $\theta_{*}$ is the scale of fluctuations for the potential temperature $\theta$. Hence, if $u_{*}$ increases, for the same $Q_{\mathrm{H}}$, care should be taken to reduce accordingly the $\theta_{*}$ in urban areas, compared to a flat surface. This implies a reduction in $z_{\mathrm{TH}}$ over urban areas. Physically the implied Peclet number is small for the following reason. The length-scale that determines $z_{\mathrm{TM}}$ is the building height (and spacing, etc.) through morphometric methods, as explained below. The roughness length for heat is determined by small-scale processes associated with the boundary layers on the building walls. Hence the very small ratio. The implied Peclet number is smaller than engineers usually encounter because the ratio of the building height to the wall boundary layer is much larger than encountered in conventional engineering flows.

In the new urban surface scheme, we use the formulation of Macdonald et al. (1998), for staggered arrays $(\beta=1)$, to compute the roughness length for momentum $z_{\mathrm{TM}}$ and displacement height $d$. When comparing seven morphometric methods to derive the roughness length and displacement height, Grimmond and Oke (1999) showed that the formulation of Macdonald was in the middle of the rankings, with the advantage that it is applicable across the full range of urban densities. For the roughness length for heat, we propose a physically based parametrization that represents $z_{\mathrm{TH}}$ as a function of the height-to-width aspect ratio $(H / W)$. The parametrization is similar to the one developed in Harman et al. (2004b), but rewritten so that the resistances are made dimensionless to avoid the use of a specific wind direction relative to canyon orientation. The latter study was validated against wind tunnel experiments, using a naphthalene sublimation technique, from Barlow and Belcher (2002) and Barlow et al. (2004). This work is summarised in the appendix.

The new component of this parametrization, compared to Harman et al. (2004b), is the derivation of the bulk roughness length for heat $z_{\mathrm{TH}}$ and implementation into the heat transfer coefficient $C_{\mathrm{H}}$, which drives the surface energy balance of the UM. The roughness length for heat $z_{\mathrm{TH}}$ is directly computed from the bulk resistances for the canyon

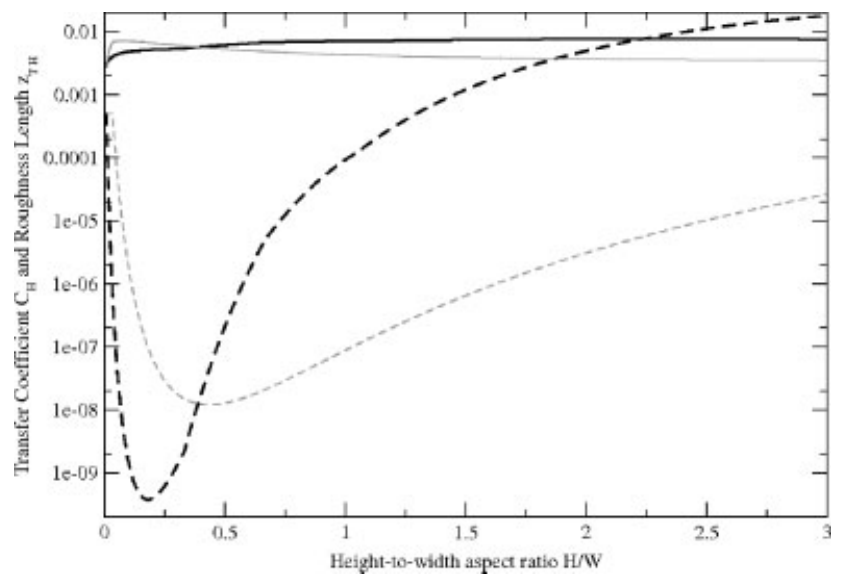

Figure 5. Model outputs of heat transfer coefficient $C_{\mathrm{H}}$ (solid lines) and of roughness length for heat $z_{\mathrm{TH}}(\mathrm{m})$ (dashed lines), as a function of height-towidth aspect ratio $(H / W)$, for canyon tile (black lines) and roof tiles (grey lines). The building height $H$ is $10 \mathrm{~m}$, the ratio of thermal to momentum material roughness lengths is $10^{-1}$ and material roughness length for momentum is $5 \times 10^{-3}$. The effective roughness length to momentum is calculated using the formulation of Macdonald et al. (1998).

$r_{\text {bulk,c }}$ and the roof $r_{\text {bulk,f }}$ using:

$$
\frac{z_{\mathrm{TH}}}{H}=\left\{z(1)+z_{\mathrm{TM}}\right\}\left[H \exp \left\{\frac{r_{\text {bulk }} k^{2}}{\ln \left(\frac{z(1)+z_{\mathrm{TM}}}{z_{\mathrm{TM}}}\right)}\right\}\right]^{-1},
$$

with $z(1)$ the first level of the atmospheric model of the MetUM. The heat transfer coefficient $C_{\mathrm{H}}$ is defined as:

$$
\frac{1}{C_{\mathrm{H}}}=\frac{1}{k^{2}} \ln \left(\frac{z(1)+z_{\mathrm{TM}}}{z_{\mathrm{TM}}}\right) \ln \left(\frac{z(1)+z_{\mathrm{TM}}}{z_{\mathrm{TH}}}\right) .
$$

Figure 5 plots $z_{\mathrm{TH}}$ and $C_{\mathrm{H}}$ separately for the canyon and the roof tiles. The maximum value of $z_{\mathrm{TH}}$, at small $H / W$, is limited to $z_{0 \mathrm{H}}=z_{0 \mathrm{M}} / 10$ with $z_{0 \mathrm{M}}=5 \times 10^{-3} \mathrm{~m}$, with $z_{0 \mathrm{H}}$ and $z_{0 \mathrm{M}}$ the material roughness lengths for heat and momentum respectively. This limit was chosen because, at small $H / W$, the bulk roughness length $z_{\mathrm{TM}}$ is limited to a minimum of $z_{0 \mathrm{M}}$. The magnitudes of $z_{\mathrm{TH}}$ reproduced here are of the same order as the ones encountered in the previous studies of Voogt and Grimmond (2000), Kanda et al. (2005) and Best et al. (2006). Note that there is no stability dependence of the roughness length or displacement height (Zilitinkevich et al., 2008). The use of a roughness length that does not depend upon stability remains the standard approach, and is the one followed here.

\subsection{Thermal inertia and coupling with soil}

We now define the two remaining terms in the energy balance of the canyon and roof tiles: the ground heat flux $G$ and the thermal inertia $C \mathrm{~d} T / \mathrm{d} t$. As introduced in section 2.1, all the tiles are coupled to the same underlying soil. This condition requires some care in the definition of these two terms. Indeed, the ground heat flux and the storage terms both contribute to a net heat flux from the surface of the urban canopy down to the underlying soil. In other words, they both contribute to the forcing boundary condition of a temperature diffusion equation which computes the temporal variation of the soil temperatures. The net heat flux will be named $G_{\mathrm{N}, j}$ per tile 
$j$. Both tiles, canyon and roof, are considered as impervious surfaces as a first approximation, so only the net heat fluxes $G_{\mathrm{N}, j}$ are considered here. To find out the appropriate forms of $G_{\mathrm{N}}$ for the canyon $G_{\mathrm{N}, \mathrm{c}}$ and the roof $G_{\mathrm{N}, \mathrm{f}}$, we first review how to express the analytical solution of the temperature diffusion equation for a slab canopy of finite thickness $\Delta z$.

\subsubsection{Analytical solution to the temperature diffusion equation}

The approach to heat fluxes into the surface and sub-surface materials is best explained by starting with the $1 \mathrm{D}$ heat transfer equation for a uniform surface:

$$
c \frac{\partial T}{\partial t}=\lambda \frac{\partial^{2} T}{\partial z^{2}} .
$$

We take $z=0$ as the surface, so the sub-surface extends to negative $z$. Defining, as above, the ground heat flux as the flux into the surface at $z=0$, we write

$$
G_{\mathrm{N}}=\left.\lambda \frac{\partial T}{\partial z}\right|_{z=0}
$$

We first consider this system driven by a single Fourier component in time with frequency $\omega$. Thus

$$
G_{\mathrm{N}}=G_{\mathrm{N} 0} \mathrm{e}^{\mathrm{i} \omega t}
$$

and

$$
T(z, t)=T_{\mathrm{m}}(z)+Z(z) \mathrm{e}^{\mathrm{i} \omega t} .
$$

This satisfies Eq. (20) if

$$
T_{\mathrm{m}}(z)=T_{\mathrm{m}}+\Gamma z
$$

with $T_{\mathrm{m}}$ and $\Gamma$ constant and

$$
Z(z)=A \gamma+B \gamma^{-1},
$$

where

$$
z_{*}=\left(\frac{2 \lambda}{\omega c}\right)^{\frac{1}{2}}
$$

and

$$
\gamma=\exp \left(\frac{(1+\mathrm{i}) z}{z_{*}}\right)
$$

Considering an infinitely thick layer, both $\Gamma$ and $B$ must be zero for finite $T$ at $z=-\infty$, leading to:

$$
T(z, t)=T_{\mathrm{m}}+A \exp \left(\frac{(1+\mathrm{i}) z}{z_{*}}\right) \exp (\mathrm{i} \omega t)
$$

The constant $A$ can be expressed in terms of the surface ground heat flux using Eqs (21) and (26):

$$
A=G_{\mathrm{N} 0} \frac{z_{*}}{\lambda(1+\mathrm{i})}=G_{\mathrm{N} 0} \frac{2}{\omega c z_{*}(1+\mathrm{i})} .
$$

At the surface, writing:

$$
T(z=0)=T_{*}=T_{\mathrm{m}}+A \mathrm{e}^{\mathrm{i} \omega t},
$$

we can write

$$
\frac{c z_{*} \omega}{2}(1+\mathrm{i})\left(T_{*}-T_{\mathrm{m}}\right)=G_{\mathrm{N}} .
$$

This expression emphasises that the relationship between surface temperature variation and ground heat flux contains a $\pi / 4$ phase shift. However, the term $i \omega T_{*}$ suggests that this can be rewritten as:

$$
\frac{c z_{*}}{2} \omega\left(T_{*}-T_{\mathrm{m}}\right)+\frac{c z_{*}}{2} \frac{\partial T_{*}}{\partial t}=G_{\mathrm{N}} .
$$

This is essentially the 'force-restore equation' (Blackadar, 1979) for a slab with uniform temperature, in the form derived by Yee (1988). This demonstrates that, for a given frequency component, the force-restore equation actually represents an exact statement of the surface energy balance for an infinite sub-surface governed by the diffusion equation, with $z_{*} / 2$ representing the equivalent depth of a slab. Yee (1988) also shows that Eq. (32) represents a depthaveraged solution, expressed in terms of surface values, provided the flux at the lower boundary is negligible.

The force-restore approach is, of course, only accurate for one given Fourier frequency. (Incidentally, Warrilow et al. (1986) showed that numerical solution of the diffusion equation using $n$ layers can also be derived which is accurate for $n$ separate Fourier frequencies.) Yee points out that, given a Fourier series of forcings, effective parameters in the force-restore equation can be derived as weighted averages of parameters for each frequency, but, in practice in a numerical model, we are unable to derive these averages in advance. We therefore choose a representative frequency (the diurnal frequency $\Omega$ ) to set the effective depth. Furthermore, the temperature $T_{\mathrm{m}}$ represents the mean temperature; in the idealised system above this equals the 'deep soil' temperature, but in practice the diurnalaverage temperature on a given day does not equal this deep soil temperature. Equation (32) can be rewritten as:

$$
\frac{\lambda}{z_{*}}\left(T_{*}-T_{\mathrm{m}}\right)+\frac{c z_{*}}{2} \frac{\partial T_{*}}{\partial t}=G_{\mathrm{N}} .
$$

In this form, $G$ is expressed as a sum of two terms. The first is a conductive coupling of the surface to a 'deep' temperature over a depth-scale $z_{*}$, while the second represents a 'canopy heat capacity' with overall areal heat capacity determined by a material thickness of half the depth and volumetric heat capacity. In this form, the frequency of the forcing does not appear explicitly (though, of course, it appears in the definition of $z_{*}$ in Eq. (26)).

This approach may be compared with that of Best (2005), which includes similar terms, but the conductive coupling is replaced by (generally weaker) radiative coupling. In practice, this may not be so inconsistent, as the heat capacity used by Best represents a large effective depthscale of material, consistent with weak coupling to deep soil temperatures. We have chosen to use the form of Eq. (33) in the representation of the storage in the urban canopy.

We can extend the above analysis to a layer of fixed depth $\Delta z$. Recalling Eqs (28) to (30) and ignoring $\Gamma$ for now, the solution may be expressed in the form:

$$
\begin{aligned}
\left\{T(z, t)-T_{\mathrm{m}}\right\}= & \left(T_{*}-T_{\mathrm{m}}\right)\left(\frac{\gamma^{-1}+\gamma}{2}\right) \\
& -G_{\mathrm{N}} \frac{z_{*}}{\lambda(1+\mathrm{i})}\left(\frac{\gamma^{-1}-\gamma}{2}\right) .
\end{aligned}
$$


If the temperature variation with time at $z=-\Delta z$ is zero, we obtain, at $z=0$,

$$
\frac{\lambda(1+\mathrm{i})}{z_{*}}\left(T_{*}-T_{\mathrm{m}}\right) f=G_{\mathrm{N}},
$$

where

$$
f=\frac{\gamma_{\Delta}^{-1}+\gamma_{\Delta}}{\gamma_{\Delta}^{-1}-\gamma_{\Delta}}
$$

and

$$
\gamma_{\Delta}=\exp \left\{-(1+\mathrm{i}) \frac{\Delta z}{z_{*}}\right\} .
$$

On the other hand, if zero flux is imposed at $z=-\Delta z$ we obtain

$$
\frac{\lambda(1+\mathrm{i})}{z_{*}}\left(T_{*}-T_{\mathrm{m}}\right) f^{-1}=G_{\mathrm{N}}
$$

The term $f$ is complex and has the effect of modifying the effective depth. For cases where $\Delta z / z_{*}>>1, f$ tends to 1 and Eq. (38) becomes the same as Eq. (31). Some insight may be gained by considering the case $\Delta z / z_{*}<<1$, in which case

$$
f \approx\left\{(1+\mathrm{i}) \frac{\Delta z}{z_{*}}\right\}^{-1} .
$$

In this case, the zero temperature variation case becomes

$$
\frac{\lambda}{\Delta z}\left(T_{*}-T_{\mathrm{m}}\right)=G_{\mathrm{N}},
$$

while the zero flux case becomes

$$
c \Delta z \mathrm{i} \omega\left(T_{*}-T_{\mathrm{m}}\right)=c \Delta z \frac{\partial T_{*}}{\partial t}=G_{\mathrm{N}} .
$$

Equations (40) and (41) resemble the two separate parts of the force-restore equation, which reinforces the interpretation of Yee (1988) that the two terms represent the flux from the deep soil associated with temperature variations accross the slab and the heating of the slab itself, with zero flux across the slab, respectively. Following this idea, we have adopted the 'canopy heat capacity' term for the two surfaces that are effectively insulated from the subsurface soil (the walls and roof) and for those surfaces in direct contact with the sub-surface soil (the road), while the conductive coupling term is used only for the latter.

Finally, it should be noted that, for finite thickness slabs, a constant temperature gradient, $\Gamma$, may be added to the solution, representing a constant flux from the lower surface due to a temperature difference $T_{\mathrm{m}}-T_{\mathrm{b}}$. In this case, an additional soil heat flux

$$
G_{\mathrm{N}}^{\prime}=\lambda \frac{T_{\mathrm{m}}-T_{\mathrm{b}}}{\Delta z}
$$

should be added to the above. This can represent conductive coupling to an internal building temperature, $T_{\mathrm{b}}$. We have not adopted this approach here, as it represents a model of at least one component of the anthropogenic heat source which we shall address separately.

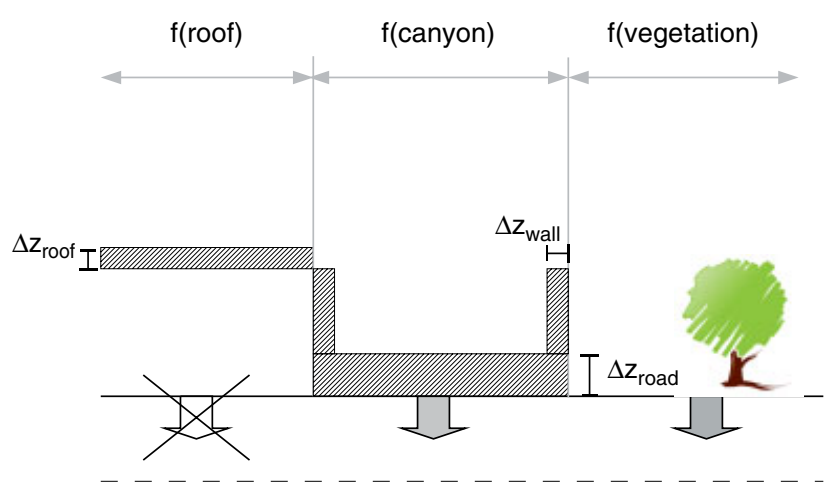

Figure 6. Schematics of coupling between a surface of the MetUM including an urban canopy and the underlying soil. This figure is available in colour online at wileyonlinelibrary.com/journal/qj

\subsubsection{Application to canyon and roof}

The previous analytical results can now be used to calculate directly the net heat fluxes for the canyon $G_{\mathrm{N}, \mathrm{c}}$ and the roof $G_{\mathrm{N}, \mathrm{f}}$. Figure 6 illustrates how these two tiles are coupled to the underlying soil.

For the canyon tile, as discussed above, the walls have a zero-flux boundary condition (Eq. (41)), while the road has the more general form of the force-restore model (Eq. (33)). Hence, the net heat flux $G_{\mathrm{N}, \mathrm{c}}$ has a conduction component from the road, as well as a storage component for the road and the walls. The conduction component $G_{\mathrm{c}}$ is expressed as:

$$
\begin{aligned}
G_{\mathrm{c}} & =-\lambda_{\mathrm{c}} \frac{\left(T_{\text {soil }}-T_{\mathrm{c}}\right)}{0.5\left(\Delta z_{\mathrm{r}}+\Delta z_{\text {soil }}\right)}, \\
\text { with } \quad \lambda_{\mathrm{c}} & =\frac{\Delta z_{\mathrm{r}}+\Delta z_{\text {soil }}}{\left(\Delta z_{\mathrm{r}} / \lambda_{\mathrm{r}}\right)+\left(\Delta z_{\text {soil }} / \lambda_{\text {soil }}\right)},
\end{aligned}
$$

with $\lambda_{c}, \lambda_{\text {soil }}$ and $\lambda_{\mathrm{r}}$, respectively the thermal conductivities for the canyon, the deep soil and road, and $T_{\mathrm{r}}$ the road temperature. Note that the road temperature $T_{\mathrm{r}}$ is equal to the canyon temperature $T_{\mathrm{c}}$.

The storage component $\left(C_{\mathrm{c}} / 2\right) \mathrm{d} T_{c} / \mathrm{d} t$ takes into account both road and wall surface area through the formulation of the areal heat capacity $C_{\mathrm{c}}$ :

$$
C_{\mathrm{c}}=2 \frac{H}{W} c_{\mathrm{w}} \Delta z_{\mathrm{w}}+c_{\mathrm{r}} \Delta z_{\mathrm{r}}
$$

with $c_{\mathrm{W}}$ and $c_{\mathrm{r}}$ the volumetric heat capacity of the walls and the road respectively. Equation (44) is normalized by the dimension $W$ to represent the heat flux density across the road width. Similarly to Eq. (26), the material thickness of each facet $i$ is formulated as:

$$
\Delta z_{i}=\left(\frac{2 \kappa_{i}}{\Omega}\right)^{1 / 2}
$$

with $\kappa$ the diffusivity of material/facet $i$. Note the use of the diurnal frequency $\Omega$. The surface energy balance for the canyon tile then follows:

$$
G_{\mathrm{N}, \mathrm{c}}=R_{\mathrm{N}, \mathrm{c}}-Q_{\mathrm{H}, \mathrm{c}}
$$

or, similarly,

$$
\beta_{\mathrm{c}} \frac{C_{\mathrm{c}}}{2} \frac{\mathrm{d} T_{\mathrm{c}}}{\mathrm{d} t}=R_{\mathrm{N}, \mathrm{c}}-Q_{\mathrm{H}, \mathrm{c}}-G_{\mathrm{c}},
$$


with $R_{\mathrm{N}, \mathrm{c}}$ defined as the sum of $R_{S}$ from section 2.3.1 and of $R_{L}$ from section 2.3.2. In Eq. (47), we also introduce $\beta_{\mathrm{c}}$, an adjustable parameter to the analytical formulation of the force-restore in Eq. (33). The latter formulation considers a substrate of infinite depth with a single and unique frequency $\omega$. Here, we develop a parametrization using a finite depth that is driven by multiple frequencies. The value of $\beta_{\mathrm{c}}$ affects the linear combination of the conduction and storage terms of Eq. (33). For $\beta_{\mathrm{c}} \neq 1$, the emphasis is placed on the phase shift of the surface temperature variation relative to the force and restore terms. The introduction of an adjustable parameter results in the definition of different combinations of frequencies for the surface temperature variation and the conduction term, which then increases the model's flexibility in capturing different oscillations. Here, we set $\beta_{\mathrm{c}}$ equal to 2 for the following reasons:

(i) The origin of the factor of $1 / 2$ in the storage term relative to the conduction term (Eq. (33)) is related to the integration of the total heat content over the slab thickness or to the definition of the soil temperature $T_{\mathrm{m}}$. When the slab thickness is large enough relative to the damping depth or $T_{*}-T_{\mathrm{m}}>$ 0 , the temperature decays exponentially within the slab. The total heat content can be approximated by a triangular distribution over the damping depth (hence the factor $1 / 2$ ). When the slab thickness is small relative to the damping depth or $T_{*}-T_{\mathrm{m}} \simeq 0$, the total heat content can be approximated by a rectangular distribution with a width equal to the slab thickness (hence no factor 1/2). Relative to the diurnal damping depth, the effective damping depth captured by the NWP model is larger because of the presence of lower frequencies. For example, the damping depth associated with a 5-day period synoptic system will lead to an increase by a factor of 2.25. When representing urban areas in NWP models, we are particularly interested in high-pressure blocking events for their impact on the Urban Heat Island (UHI) since these are often associated with extended periods of light winds and clear skies.

(ii) In point (i), we argued that the material thickness is smaller than the effective damping depth, due to the presence of lower frequencies. In these conditions, by setting $\beta_{\mathrm{c}}$ to 2 , the modelled thickness of the urban canopy becomes equal to the value of the diurnal damping depth for the urban fabric. The magnitude of the diurnal damping depth for a typical soil is around $0.1 \mathrm{~m}$ (Garratt, 1994). This magnitude is similar to the values of urban material thickness used in the study of Dupont and Mestayer (2006).

(iii) The value of the adjustable parameter $\beta_{\mathrm{c}}$ also depends on the geometry. Urban facades are generally covered by inhomogeneities that could potentially lead to an increase of their surface area, and hence their heat content, thus increasing the effective heat capacity.

(iv) In the urban canopy parametrization of Dupont and Mestayer (2006), the ratio between the surface temperature variation term and the conduction term is also equal to $1\left(=\beta_{\mathrm{c}} / 2\right.$, with $\left.\beta_{\mathrm{c}}=2\right)$.

For the roof tile, following Eq. (41), the zero-flux boundary condition leads to the absence of any conductive coupling, which gives the following parametrization of the storage heat flux:

$$
G_{\mathrm{N}, \mathrm{f}}=\frac{\beta_{\mathrm{f}}}{2} c_{\mathrm{f}} \Delta z_{\mathrm{f}} \frac{\mathrm{d} T_{\mathrm{f}}}{\mathrm{d} t},
$$

with $\Delta z_{\mathrm{f}}$ the roof thickness following Eq. (45) and $\beta_{\mathrm{f}}$ an adjustable parameter. Similarly to the canyon paramater $\beta_{\mathrm{c}}$, the value of $\beta_{\mathrm{f}}$ is set to 2 . Note that these values of areal heat capacity (canyon and roof) are comparable to the value used in the Best scheme, as explained in the next section.

The surface energy balance for the roof tile then becomes:

$$
\frac{\beta_{\mathrm{f}}}{2} c_{\mathrm{f}} \Delta z_{\mathrm{f}} \frac{\mathrm{d} T_{\mathrm{f}}}{\mathrm{d} t}=R_{\mathrm{N}, \mathrm{f}}-Q_{\mathrm{H}, \mathrm{f}}
$$

with

$$
R_{\mathrm{N}, \mathrm{f}}=\left(1-\alpha_{\mathrm{f}}\right) S_{\text {incident }}+\varepsilon_{\mathrm{f}}\left(L W^{\downarrow}-\sigma T_{\mathrm{f}}^{4}\right),
$$

with $c_{\mathrm{f}}$ the volumetric heat capacity $\left(\mathrm{J} \mathrm{K}^{-1} \mathrm{~m}^{-3}\right)$. We define an areal heat capacity $C_{\mathrm{f}}$ as the product $c_{\mathrm{f}} \Delta z_{\mathrm{f}}$. Sensitivity analysis to $\Delta z_{\mathrm{f}}$ for insulation roof material will be conducted in section 3.3 and in Part II.

To take into account the fact that only the canyon tile is coupled to the soil, the total heat flux $G_{\mathrm{N}}$ per planar area is given by:

$$
G_{\mathrm{N}}=\sum_{j, \text { non-urban }} f(j) G_{j}+\frac{f_{\mathrm{c}}+f \mathrm{r}}{f_{\mathrm{c}}} G_{\mathrm{c}}
$$

with $f(j)$ the cover fraction of tile $j$ per grid box.

Lastly, as mentioned earlier, the equations described in this section are formulated for impervious surfaces. Urban surfaces in MORUSES, as well as in the Best scheme, can be made pervious by allowing for non-zero values of the water capacity of the urban tiles. The latent heat flux can also be increased by increasing the canopy conductance to evaporation. Moisture fluxes within the soil substrate may then have an important contribution in the evolution of the soil and surface temperatures. These moisture processes are also neglected in the following idealized simulations. The impact of soil moisture and water infiltration on the urban energy balance should be considered for future work.

\section{Idealized simulations}

\subsection{Motivation and set-up of the simulations}

In these idealized simulations, our motivation is to isolate the impact of each urban process, described in section 2, relative to the energy balance of a flat surface. When all the urban processes are included, the flat surface is equivalent to an urban surface represented with the new scheme. To reach this goal, we created very specific idealized conditions. Our urban cover is assumed to be infinitely long. We want our system to evolve solely by diurnal short-wave radiation. We work therefore in dry conditions, which results in very small (and probably unrealistic) values for downward long-wave radiation. We specify conditions which initially produce long-wave, turbulent and ground heat fluxes close to zero to avoid large initial transients.

To address these criteria, the following paragraph details the special set-up of these idealized simulations. The new scheme was incorporated into the 3D Unified Model code 
Table II. Input parameters for bare soil surface.

\begin{tabular}{lll}
\hline Symbol & Units & Value \\
\hline$\alpha$ & & 0.30 \\
$\varepsilon$ & & 0.97 \\
$C$ & $\mathrm{~J} \mathrm{~m}^{-2} \mathrm{~K}^{-1}$ & 0.00 \\
Bulk roughness length & $\mathrm{m}$ & $5 \times 10^{-3}$ \\
for momentum & & $10^{-1}$ \\
$\begin{array}{l}\text { Ratio of roughness lengths } \\
\text { (heat to momentum) }\end{array}$ & \\
\hline
\end{tabular}

at $1 \mathrm{~km}$ horizontal resolution. A domain of $64 \times 64 \mathrm{~km}$ was centred around London, and the land-use class was modified in order to obtain a classification of $100 \%$ urban. The vertical domain was kept identical to the full 3D UM, $40 \mathrm{~km}$ depth with 76 vertical levels with spacing varying quadratically in the troposphere. The bottom temperature level is at $5 \mathrm{~m}$, and the next at $20 \mathrm{~m}$. The model runs with bicyclic lateral boundary conditions, so the simulation is not affected by any advection caused by differences in source area characteristics (at the opposite extreme to surfaceonly models, for which the forcing in observations may include such advection). The ozone vertical profiles were horizontally averaged to guarantee horizontal homogeneity in solar forcing. Evaporation is forced to 0 by suppressing the surface conductance and mimimizing the canopy water availability. Initially, the soil and atmosphere are set up to identical temperature conditions: the soil temperature profile is isothermal with a temperature $T_{i}$; the atmospheric profile is (dry) adiabatic up to $1000 \mathrm{~m}$ (with an inversion of $12^{\circ} \mathrm{C}$ ), and isothermal above $1000 \mathrm{~m}$ with a temperature $T_{i}$. The temperature $T_{i}$ was chosen so that the average net solar radiation at the surface balances the average emitted long-wave radiation:

$$
<\operatorname{Net} S W>=<\sigma T_{\mathrm{s}}^{4}>=\sigma T_{i}^{4},
$$

With solar forcing conditions from mid-July for the flat surface, $T_{i}$ was evaluated to $277 \mathrm{~K}$ (this value was chosen for the rest of the simulations). The simulations are initialized at 0600 local standard time (when fluxes are minimal) and run for three days.

\subsection{Impact of urban processes on energy balance fluxes}

In order to investigate the impact of the new parametrization, we add, to a flat bare surface, a perturbation induced by a specific urban process: albedo, emissivity, heat transfer and roughness to momentum, thermal inertia and coupling with the soil. The input parameters for the flat bare soil are shown in Table II, and the input parameters for the Best scheme and the new scheme are shown respectively in Tables III and IV. Values are taken from Oke (1987) and Masson et al. (2002).

The perturbation to the flat surface fluxes induced by the emissivity is weak, and is not shown (using Eq. (17), a bulk emissivity value of 0.973 is calculated, while a default value of 0.97 is used for the flat surface). Figure 7 illustrates the surface energy balance flux densities, averaged over a 3-day period, separately for the flat bare soil only, for the flat bare soil with bulk albedo (subsection 2.3.1), the flat bare soil with heat transfer (subsection 2.4) and for the flat bare
Table III. Input parameters for default current scheme.

\begin{tabular}{lll}
\hline Symbol & Units & Value \\
\hline$\alpha$ & & 0.18 \\
$\varepsilon$ & $\mathrm{J} \mathrm{m}^{-2} \mathrm{~K}^{-1}$ & 0.97 \\
$C$ & $\mathrm{~m}$ & $0.28 \times 10^{6}$ \\
$\begin{array}{l}\text { Bulk roughness length } \\
\text { for momentum }\end{array}$ & $10^{-7}$ \\
$\begin{array}{l}\text { Ratio of roughness lengths } \\
\text { (heat to momentum) }\end{array}$ & \\
\hline
\end{tabular}

Table IV. Input parameters for new scheme.

\begin{tabular}{|c|c|c|}
\hline Symbol & Units & Value \\
\hline$\overline{C_{\mathrm{r}}}$ & $\mathrm{J} \mathrm{m}^{-3} \mathrm{~K}^{-1}$ & $1.94 \times 10^{6}$ \\
\hline$\Delta z_{\mathrm{r}}$ & $\mathrm{m}$ & 0.11 \\
\hline$C_{\mathrm{w}}$ & $\mathrm{J} \mathrm{m}^{-3} \mathrm{~K}^{-1}$ & $1.37 \times 10^{6}$ \\
\hline$\Delta z_{\mathrm{w}}$ & $\mathrm{m}$ & 0.13 \\
\hline$C_{\mathrm{f}}$ & $\mathrm{J} \mathrm{m}^{-3} \mathrm{~K}^{-1}$ & $1.50 \times 10^{6}$ \\
\hline$\Delta z_{\mathrm{f}}$ & $\mathrm{m}$ & 0.13 \\
\hline$\alpha_{\mathrm{r}}$ & & 0.08 \\
\hline$\alpha_{\mathrm{w}}$ & & 0.50 \\
\hline$\alpha_{\mathrm{f}}$ & & 0.18 \\
\hline$\varepsilon_{\mathrm{r}}$ & & 0.95 \\
\hline$\varepsilon_{\mathrm{w}}$ & & 0.90 \\
\hline$\varepsilon_{\mathrm{f}}$ & & 0.92 \\
\hline Building height & $\mathrm{m}$ & 10 \\
\hline Material roughness length & $\mathrm{m}$ & 0.005 \\
\hline$\lambda_{\text {soil }}$ & $\mathrm{W} \mathrm{m} \mathrm{m}^{-1} \mathrm{~K}^{-1}$ & 0.22 \\
\hline$\lambda_{\mathrm{r}}$ & $\mathrm{W} \mathrm{m} \mathrm{m}^{-1} \mathrm{~K}^{-1}$ & 0.75 \\
\hline$H / W$ & & 1.0 \\
\hline$W / R$ & & 0.5 \\
\hline
\end{tabular}

Data are taken from Oke (1987), Masson et al. (2002).

Wall material $(\mathrm{w})$ is brick,

road material $(\mathrm{r})$ is asphalt/concrete,

and roof material $(\mathrm{f})$ is concrete/stone.

soil following the thermal inertia and coupling with soil in subsection 2.5. We chose not to include the second part of the night on these graphs in order to focus more on the large differences occurring at daytime and dusk. The idealized set-up we use results in very small downward long-wave radiation, and important radiation loss at night-time. The loss of radiation results in a drop of surface temperature at night-time and large values of storage heat flux are therefore needed after dawn, to elevate the canopy temperature above the air temperature. In these conditions, the energy balance for the flat case has relatively large storage heat flux and the sensible heat flux peaks relatively later in the day than one may expect from a flat surface. Sensible heat flux densities at night-time tend to zero because of the choice in the stability dependence of the diffusion heat coefficients in the stable case. (By default, a function of the bulk Richardson number is used, which acts to decouple the surface from the atmosphere beyond a critical $R i$.)

We will now go through each of these urban processes separately. Due to the reduced effective albedo, the perturbation induced by the bulk albedo process leads to an increase in net radiation and sensible heat flux, compared 

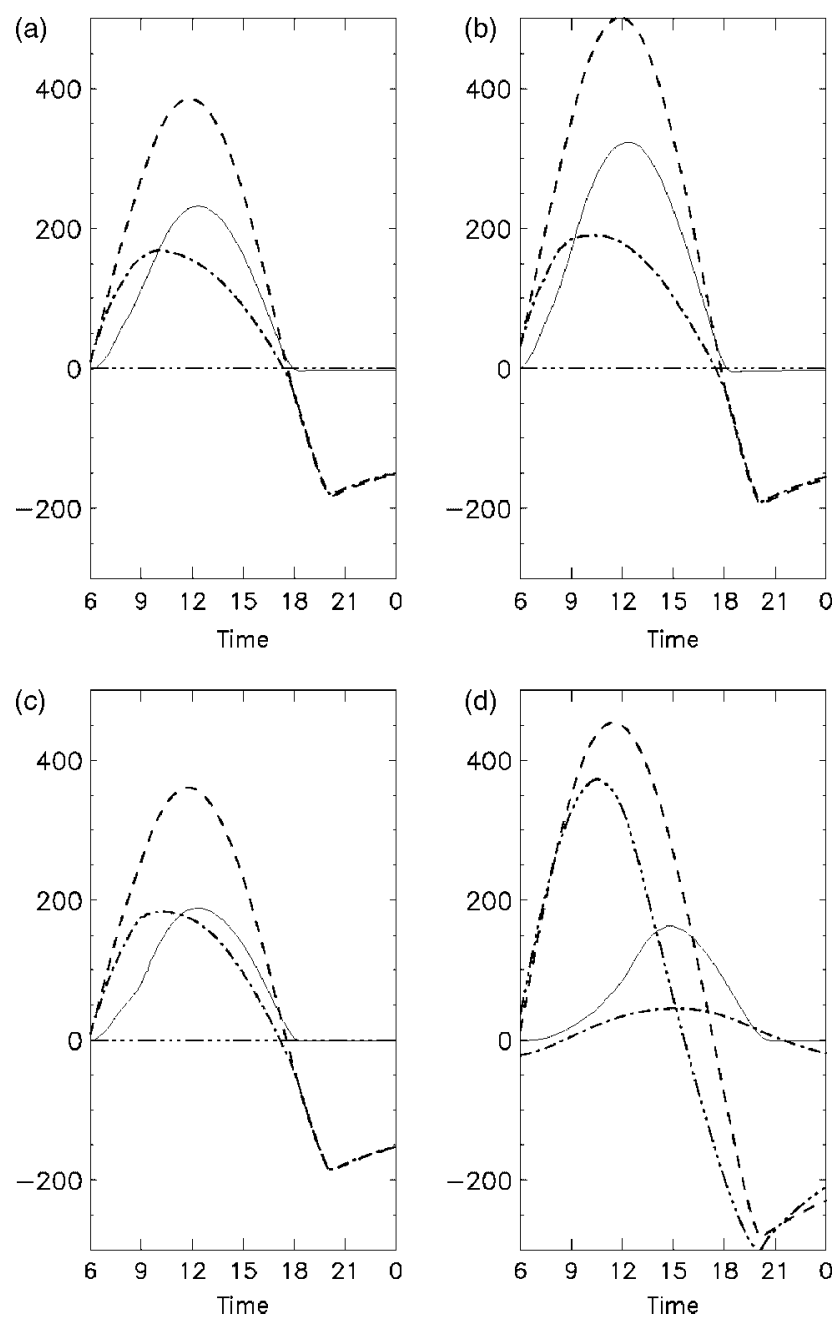

Figure 7. Idealized MetUM outputs of surface energy balance flux densities $\left(\mathrm{W} \mathrm{m}^{-2}\right.$ ) for (a) flat bare soil perturbed separately by three urban processes: (b) albedo, (c) heat transfer, and (d) thermal inertia and coupling with soil. Net radiation (dashed line), sensible heat (solid line), heat to deep soil (dot-dashed line), storage heat (triple dot-dashed line). See text for further explanation.

to the flat surface case. The perturbation induced by heat transfer and roughness results in slightly smaller values of $Q_{H}$, and higher values of conduction $G$. Compared to the undisturbed flat case, the smaller values of $Q_{H}$ result from weaker wind speeds above the urban canopy (as a consequence of high roughness to momentum), despite the larger values of heat transfer coefficients $C_{\mathrm{H}}$ $\left(Q_{\mathrm{H}} \approx U(1) C_{\mathrm{H}} \Delta T\right)$. Lastly, the perturbation induced by the combination of thermal inertia and coupling with the underlying soil leads to a decrease in the conductive heat flux with the soil and to the introduction of a large storage heat flux. The introduction of the storage heat flux causes a significant phase delay in the sensible heat flux as well as a significant increase in the net radiation, compared to the flat case. Following Harman and Belcher (2006), the high inertia dampens the diurnal amplitude of surface temperature. After dawn, it takes longer for the surface temperature to become larger than the air temperature; hence, the phase delay in the sensible heat. The difference in net radiation is explained by the difference in upward long-wave radiation as in Best et al. (2006). The smaller conductive heat flux is associated with smaller surface temperatures, which leads to smaller temperature differences between the urban canopy and the
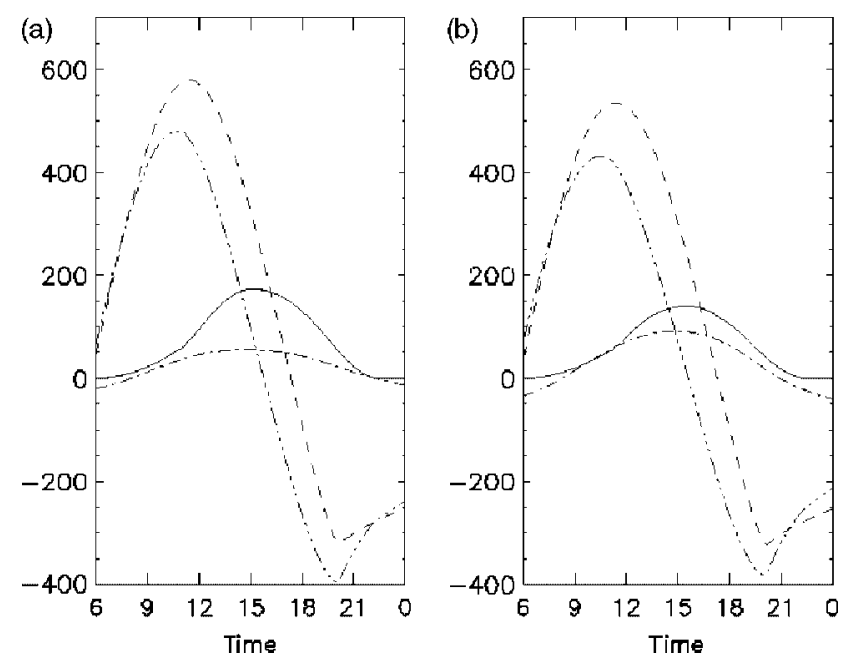

Figure 8. Idealized MetUM outputs of surface energy balance flux densities $\left(\mathrm{W} \mathrm{m}^{-2}\right)$ for (a) the new scheme with flat bare soil perturbed by four urban processes together (albedo, emissivity, heat transfer, thermal inertia and coupling with soil), and (b) the Best scheme. The line styles are as in Figure 7. See text for further explanation.

first soil layer. Out of the three perturbations illustrated in Figure 7, the combination of thermal inertia and coupling with soil has the largest impact on the energy balance fluxes.

Next, in Figure 8, we show the perturbations to the flat surface induced by the combination of all the urban processes, compared to the current urban scheme. The perturbation represents now the new scheme (indeed, nothing is left from the flat surface). The comparison of the new scheme with the current scheme shows promising results: the surface energy balance fluxes from the two schemes are similar. This is encouraging because, as mentioned in the introduction, our main goal, at this stage, is to reproduce the characteristics of the current scheme while using measurable properties representative of urban material, and allowing for a sensitivity to canyon geometry so that the new scheme is more adaptable to other situations.

There are, nevertheless, slight differences between the schemes which we shall now explain. From Figure 8, the current scheme produces slightly less heat storage than the new scheme. The Best scheme uses a bulk heat capacity value of $0.28 \mathrm{~J} \mathrm{~K}^{-1} \mathrm{~m}^{-2}$. For a $H / W$ value of 1 and from Table IV, the canyon heat capacity is roughly $0.6 \mathrm{~J} \mathrm{~K}^{-1} \mathrm{~m}^{-2}$, while the roof heat capacity is roughly $0.15 \mathrm{~J} \mathrm{~K}^{-1} \mathrm{~m}^{-2}$. Together, for a value of $W / R$ of 0.5 , an approximated bulk value of $0.375 \mathrm{~J} \mathrm{~K}^{-1} \mathrm{~m}^{-2}$ can be calculated by area-weighted average. Further to subsection 2.3.1, the albedo for the current scheme is, however, higher (0.18) than the approximated combination of the bulk canyon value used by the new scheme (Figure 3 for $H / W=1$ ) and of the roof albedo (0.20). The smaller albedo values for the new scheme lead to higher values of net radiation and sensible heat fluxes. Despite these slight differences, the grid-box surface temperatures are almost equal between the two schemes. This is illustrated in Figure 9. In this figure, we show that the two gridbox surface temperatures are almost identical (maximum difference reaches 1.4 around 21.00). We also show the larger diurnal amplitudes in the roof surface temperature, compared to the canyon as in Porson et al. (2009).

From Figure 9, we can also explain the differences in heat flux $G$ between the two schemes. The Best scheme uses a radiative exchange of long-wave radiation between the first 


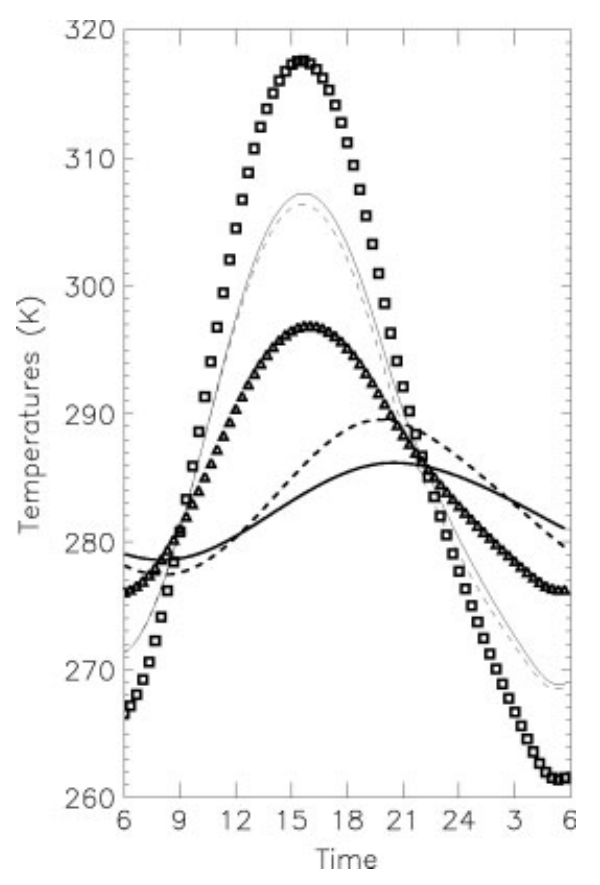

Figure 9. Idealized MetUM outputs of surface temperatures (gridbox and tile) and soil temperatures (K): the new scheme (solid lines), the Best scheme (dashed lines), gridbox temperatures (thin lines), first level soil temperatures (bold lines), roof surface temperature (squares), canyon surface temperature (triangles). See text for further explanation.

soil layer and the surface temperature of the urban canopy (Eq. (6)). At a first order of approximation, this difference in long-wave radiation can be written as a linear difference between the first layer soil temperature and the surface temperature of the urban canopy. In this approximation, $G$ becomes equivalent to the conductive formulation used in the new scheme (Eq. (43)), but with the major difference that for the new scheme, the surface temperature is the canyon temperature (triangles in Figure 9), while, for the Best scheme, the surface temperature is the grid-box temperature (dashed line in Figure 9). This major difference explains why the conduction heat flux $G$ is smaller in the new scheme and why the diurnal amplitude of the first soil layer temperature is also smaller in the new scheme.

\subsection{Sensitivity analysis}

In the following section, we describe a sensitivity analysis of the new scheme and compare our results of surface energy balance fluxes to the current scheme. Let us recall here that the current scheme is 'frozen' since its parameterization does not depend on canyon geometry.

Firstly, we will investigate the sensitivity to geometry and produce idealized simulations of the new scheme for varying values of $H / W$ ( $W / R$ fixed) and vice-versa.

Figure 10 shows the sensible heat flux $Q_{\mathrm{H}}$ and heat storage flux $C \mathrm{~d} T / \mathrm{d} t$ for increasing values of $H / W$. Consistently with the calculation of $C_{\mathrm{c}}$ (Eq. (46)), the increase in $H / W$ results in a higher heat storage. Higher heat storage goes with decreasing magnitudes and increasing phase delays of sensible heat flux. Compared to the Best scheme (thick lines), the new scheme stores more heat (as discussed in sub-section 3.2). With the exception of small $H / W$, the Best scheme storage flux densities are systematically smaller in magnitude. This systematic deviation also occurs for the conduction heat flux $G$ : increasing values of $H / W$ leads to (a)

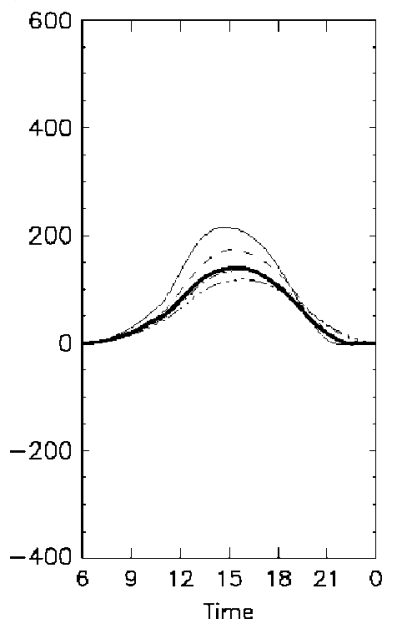

(b)

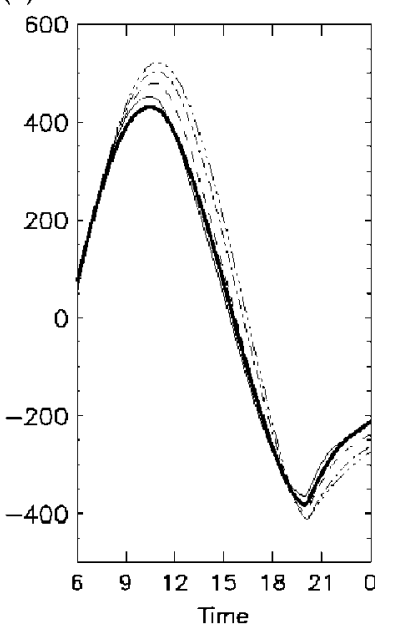

Figure 10. Idealized MetUM outputs of (a) sensible and (b) heat storage fluxes $\left(\mathrm{W} \mathrm{m}^{-2}\right)$ for $W / R=0.5$ and increasing values of $H / W$ : Best scheme (thick solid line), new scheme with $H / W$ values 0.5 (thin solid line), 1.0 (dashed line), 2.0 (dash-dotted line), and 3.0 (dash-triple dotted line). See text for further explanation.

\section{(a)}

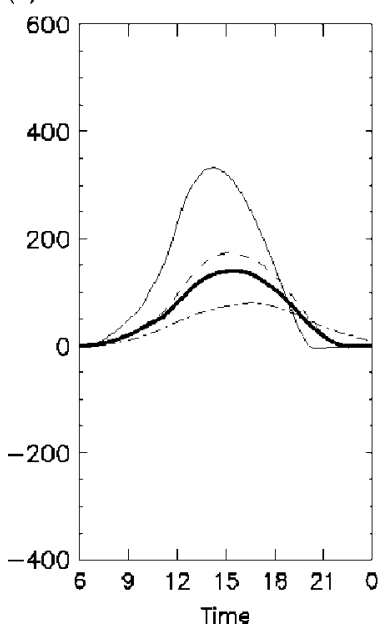

(b)

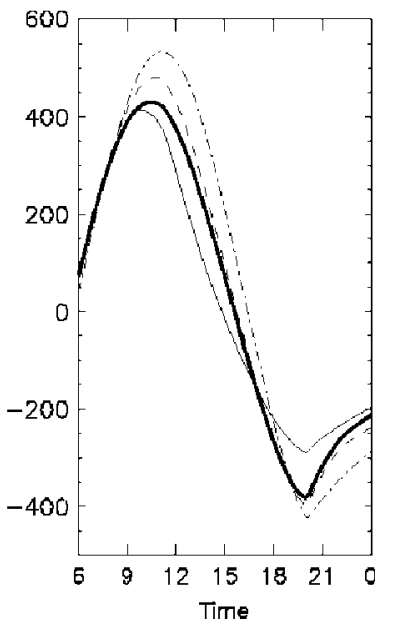

Figure 11. Idealized MetUM outputs of (a) sensible and (b) heat storage fluxes $\left(\mathrm{W} \mathrm{m}^{-2}\right)$ for $H / W=1$ and increasing values of $W / R$ : Best scheme (thick solid line), new scheme with $W / R$ values 0.1 (thin solid line), 0.5 (dashed line), and 0.9 (dash-dotted line). See text for further explanation.

systematically smaller $G$ values for the new scheme than for the Best scheme, due to a decrease in the diurnal amplitude of the canyon temperature in the new scheme (not shown). The magnitudes of the sensible heat flux $Q_{H}$ from the Best scheme are, however, included within the sensitivity range of the magnitudes of $Q_{H}$ from the new scheme. Overall, the sensitivity analysis to the large range of $\mathrm{H} / \mathrm{W}$ values ( 0.1 to 3.0 ) reveals a significant impact on the energy balance (fluxes vary by a factor of 2). This impact remains, however, smaller than the impact on the energy balance due to variations in W/R.

Similarly to Figure 10, Figure 11 plots the sensible heat flux $Q_{\mathrm{H}}$ and heat storage flux $C \mathrm{~d} T / \mathrm{d} t$ for $W / R$ varying from 0.1 to $0.9(H / W$ is fixed to 1$)$. The sensitivity of the energy balance of the new scheme is much larger for varying $W / R$ than for varying $H / W$. The analysis of these results is based on the physical differences between the canyon and the roof tiles. For small values of $W / R$, the roof fraction is much larger than the canyon fraction. The roof tile has a smaller heat capacity, which leads to large diurnal amplitudes in 

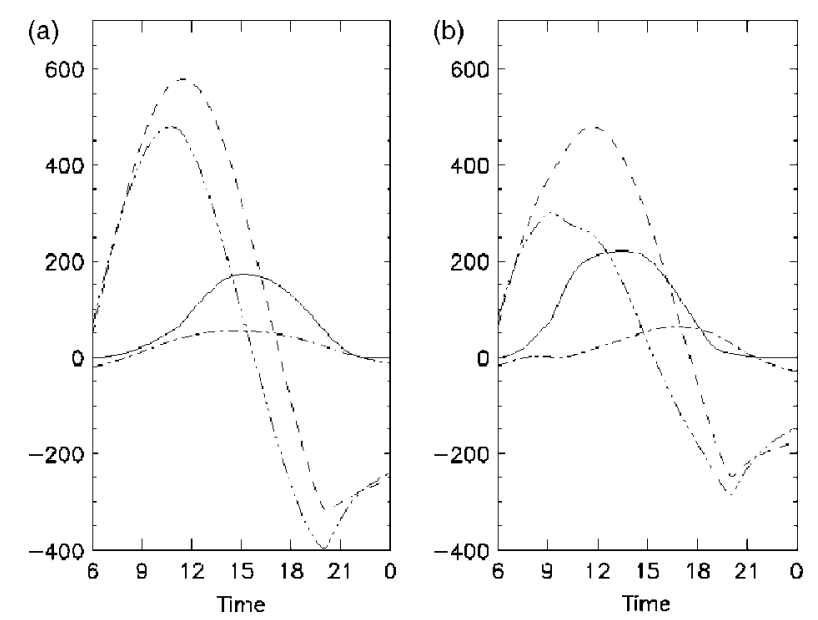

Figure 12. Idealized MetUM outputs of surface energy balance fluxes $\left(\mathrm{W} \mathrm{m}^{-2}\right)$ for the new scheme with (a) thick and (b) thin roofs. The line styles are as in Figures 7 and 8. See text for further explanation.

surface temperature, large temperature gradients, and so large $Q_{H}$. In these conditions ( $W / R$ small), $Q_{H}$ is large, while the storage term $C \mathrm{~d} T / \mathrm{d} t$ is small. At the other end of the range $(W / R$ large), the canyon fraction is much larger than the roof fraction. The large heat capacity of the canyon tile results in small temperature gradients, small $Q_{H}$ and large $C \mathrm{~d} T / \mathrm{d} t$. These results are in agreement with Harman and Belcher (2006). They showed that the air temperatures reach larger diurnal amplitudes when the roof fraction is high (small $W / R$ ), which is equivalent to saying the sensible heat flux is larger when the roof fraction is high. The result for large $W / R$ depends critically on the assumption about the properties of the non-roof part of the domain. The results here assume that the whole of that area is road. However, if it were bare soil, the answers would be very different.

The last sensitivity study from this work deals with the sensitivity to the roof thermal properties. Note that the roof material provides all of the thermal inertia of the roof part of the system. In so-doing, we are assuming that the roof is well insulated from the interior of the building. This is clearly an ideal which many building designs seek to achieve, but other designs may correspond more to 'thick roof behaviour. In the case of a well-insulated roof space, roof thermal conductivity and diffusivity are small. To take this effect into account, we set the roof thickness $\left(\sim \kappa_{\mathrm{f}}^{1 / 2}\right)$ to an arbitrary small value of $0.02 \mathrm{~m}$. The small roof thickness reduces the magnitude of the areal heat capacity, which in turn leads to significantly smaller net radiation, larger and earlier sensible heat fluxes. Figure 12 illustrates these effects by plotting the global energy balance fluxes for two cases: one, for a roof energy balance using Eq. (45) (thick roof) and two, for a roof thickness set to $\Delta z_{\mathrm{f}}=0.02 \mathrm{~m}$ (thin roof). The new scheme is very sensitive to this type of information, and the roof thickness will be a key factor when the models performance is compared with observations. Part II of this study will compare this work to observations.

\section{Conclusions}

In this paper, we developed and implemented a new urban surface scheme, MORUSES (Met Office Reading Urban Surface Exchange Scheme), into the Met Office Unified Model. The new scheme includes the following urban processes: formulation of a roughness length for heat using a resistance network, formulation of a roughness length for momentum following the morphometric method of Macdonald et al. (1998), bulk values of albedo and emissivity deriving from the exact numerical solution to the exchange of diffuse radiation in a $2 \mathrm{D}$ canyon geometry, increase in heat storage in the canyon tile, and conductive coupling with the underlying soil using material properties from the road surface.

Our first objective is to ensure that the bulk outputs from the new scheme are in agreement with previous studies. The bulk albedo values show similar tendencies with previous Monte-Carlo methods for varying geometry parameters, except at small $H / W$ where the impact of heterogeneity between the canyon facets is significant. Concerning the heat transfer, the resistance network allows us to capture the magnitudes of roughness length for heat as small as in previous studies $\left(\mathrm{O}\left(10^{-7} \mathrm{~m}\right)\right)$. Lastly, concerning the thermal inertia, we formulate an effective heat capacity for each urban tile as a function of material damping depth and volumetric heat capacity values. The resulting bulk value, combining roof and canyon, is similar to the current scheme's default value.

Our second objective is to ensure that the energy balance of the new scheme is consistent with the energy balance of the current scheme for similar overall parameters. A series of idealized simulations is then performed. The simulations show that the energy balance of the new scheme reflects the urban processes as well as in the current scheme. In particular, the surface temperature of the two schemes is remarkably similar.

Our third objective is to analyse the impact of each urban process on the energy balance fluxes. To evaluate the impact of each process, we perturb a flat surface and compare the energy balance of the disturbed surface to the energy balance of the flat surface. The implementation of thermal inertia and conductive coupling with the underlying soil has the biggest impact on the surface fluxes: leading to smaller magnitudes and later peaks in sensible heat and conductive heat, high contribution in heat storage, higher net radiation due to larger heat capacity values. This suggests that the new scheme will be sensitive to any modification introduced in these processes.

Our fourth objective is to test the new scheme for varying geometry parameters as the height-to-width aspect ratio $H / W$ and the canyon width to urban width aspect ratio $W / R$. The new scheme is less sensitive to $H / W$ than to $W / R$. However, increasing $H / W$ or $W / R$ results in the same impact. Indeed, increasing $H / W$ leads to a stronger impact of thermal inertia, i.e. increasing magnitudes and later peak values in the sensible heat, as well as higher magnitudes of heat storage. Increasing $W / R$ leads to a smaller contrubution of the roof tile, and respectively a larger contribution from the canyon tile, which also leads to smaller magnitudes and later peak values in sensible heat, as well as larger magnitudes of heat storage.

Lastly, our final objective is to study the sensitivity of the new scheme to the roof parameters. The new scheme is sensitive to the roof fraction of the urban canopy, due to the contrast in the thermal inertia between the roof and the canyon tile. This contrast is even stronger for insulated roof properties, which use small conductivity and heat capacity values. As a test for insulation, we repeat some idealized simulations with smaller roof thickness (smaller heat capacity values). Significant differences appear in the 
sensible heat and heat storage fluxes, in coherence with decreasing heat capacity values. The new scheme is therefore highly sensitive to the roof properties. In part II, the comparison of the new scheme against measurements of surface fluxes will be tested, as well as the new scheme's sensitivity to roof thickness.

\section{Acknowledgements}

The authors are grateful to Richard Forbes and Changgui Wang for their help in setting up the idealised MetUM simulations. The authors would like to take the opportunity to thank Brian Golding for his fruitful comments for finalising these papers before submission. Finally, the authors are grateful to Gabriel Rooney and David Thomson for their help during the revision process.

\section{Appendix}

\section{A1. Derivation of canyon bulk emissivity}

Following a similar procedure to the one leading to Eqs (12) to (14), we can derive the net long-wave radiation $R_{L, i}$ for each facet $i$ through the following set of equations following Harman et al. (2004):

$$
B_{i}=\sum_{j} \Psi_{i j}^{\prime} L_{j}^{\downarrow \uparrow},
$$

$$
\begin{aligned}
& \text { with } \begin{aligned}
\left(\Psi_{i j}^{\prime}\right)^{-1} & =\delta_{i j}-\left(1-\varepsilon_{i}\right) F_{i j}, \quad i, j=1,2,3 \\
R_{L, i} & =\Lambda_{i}-B_{i}, \\
\text { with } \Lambda_{i} & =\sum_{j} F_{i j} B_{j}, \quad i, j=1,2,3
\end{aligned}
\end{aligned}
$$

and

$$
\begin{aligned}
R_{L, i} & =\sum_{j}\left(\frac{\delta_{i j}-\Psi_{i j}^{\prime}-1}{1-\varepsilon_{i}}\right) B_{j}-B_{i}=\frac{B_{i}-L_{i}^{\downarrow \uparrow}}{1-\varepsilon_{i}}-B_{i} \\
& =\frac{\varepsilon_{i} B_{i}-L_{i}^{\downarrow \uparrow}}{1-\varepsilon_{i}}, \quad i, j=1,2,3 .
\end{aligned}
$$

The net long-wave radiation for the canyon tile $R_{L}$ is the weighted sum, according to canyon geometry, of $R_{L, \mathrm{r}}$ and $R_{L, \mathrm{w}}$ being:

$$
\begin{aligned}
R_{L, \mathrm{c}} & =R_{L, \mathrm{r}}+\frac{2 H}{W} R_{L, \mathrm{w}}, \\
R_{L, \mathrm{r}} & =\frac{\varepsilon_{\mathrm{r}}\left(\Psi_{\mathrm{r}, \mathrm{r}}^{\prime} L_{\mathrm{r}}^{\downarrow \uparrow}+\Psi_{\mathrm{r}, \mathrm{w}}^{\prime} L_{\mathrm{w}}^{\downarrow \uparrow}+\Psi_{\mathrm{r}, \mathrm{sky}}^{\prime} L_{\mathrm{sky}}^{\downarrow \uparrow}\right)-L_{\mathrm{r}}^{\downarrow \uparrow}}{1-\varepsilon_{\mathrm{r}}}, \\
R_{L, \mathrm{w}} & =\frac{\varepsilon_{\mathrm{w}}\left(\Psi_{\mathrm{w}, \mathrm{r}}^{\prime} L_{\mathrm{r}}^{\downarrow \uparrow}+\Psi_{\mathrm{w}, \mathrm{w}}^{\prime} L_{\mathrm{w}}^{\downarrow \uparrow}+\Psi_{\mathrm{w}, \mathrm{sky}}^{\prime} L_{\mathrm{sky}}^{\downarrow \uparrow}\right)-L_{\mathrm{w}}^{\downarrow \uparrow}}{1-\varepsilon_{\mathrm{w}}} .
\end{aligned}
$$

Rearranging Eqs (16), (A4), (A5) and (A6), the net longwave radiation for the canyon tile $R_{L, \mathrm{c}}$ can be reformulated as:

$$
R_{L, \mathrm{c}}=\varepsilon L W^{\downarrow}-\varepsilon \sigma T_{\mathrm{c}}^{4},
$$

with $\varepsilon$ the canyon bulk emissivity.

\section{A2. Derivation of canyon and roof bulk resistances}

For the canyon tile, following Harman et al. (2004b), we represent three types of flow regimes: the isolated roughness regime where the canyon flow is affected both by a recirculation and a ventilation region, a wake interference flow regime and a skimming flow regime where ventilation is minimum. In each case, we have two resistances built in parallel: $r_{\text {recirc }}$ for the recirculation region and $r_{\text {venti }}$ for a potential ventilated region where exchange of air between the canyon and the atmosphere above is dominant. An internal length-scale $L_{\mathrm{r}}$ is given as an input parameter to limit the length of the recirculation region.

Each of these resistance systems, $r_{\text {recirc }}$ and $r_{\text {venti }}$, incorporates three sub-resistances (Figure 5 in Harman et al., 2004b). Two of these sub-resistances represent the transfer of heat across an internal boundary layer, adjacent to each facet and expressed as:

$$
\begin{aligned}
r_{\mathrm{int}, i} & =\frac{1}{f_{\delta_{i}} k^{2}} \ln \left(\frac{\delta_{i}+z_{0 \mathrm{M}}}{z_{0 \mathrm{M}}}\right) \ln \left(\frac{\delta_{i}+z_{0 \mathrm{M}}}{z_{0 \mathrm{H}}}\right), \\
\text { with } f_{\delta_{i}} & =\frac{u\left(\delta_{i}\right)}{U_{\mathrm{ave}}(1)}, \text { and } i=\text { facet indicator, }
\end{aligned}
$$

where $U_{\text {ave }}$ represents the orientationally averaged wind:

$$
U_{\mathrm{ave}}(1)=\frac{2}{\pi} U(1),
$$

and $\delta_{i}$ the depth of the internal layer adjacent to the facet considered, $z_{0 \mathrm{M}}$ is the material roughness length for momentum, $z_{0 \mathrm{H}}$ is the material roughness length for heat, $u$ is the wind speed component of the atmospheric model, and $k$ is the von Kármán constant. The ratio $f_{\delta_{i}}$ depends on the facet itself and the type of region: $f_{\delta_{i}}$ relies on the derivation of the jet speeds within the canyon. To complete the network, the sub-resistances $r_{\text {int, } i}$ from two adjacent facets (i.e. upstream wall and road fraction affected by recirculation region) are built in parallel and connected in series to a third sub-resistance $r_{\text {inert }}$ that represents the transfer of heat across the inertial sub-layer, expressed as:

$$
r_{\text {inert }}=\frac{\left(1-f_{\delta}\right)}{k^{2}} \ln \left(\frac{z(1)+z_{\mathrm{TM}}}{z_{\mathrm{TM}}}\right) .
$$

Across the inertial sublayer, the transfer of heat is affected by the bulk properties of the canyon as the bulk roughness length $z_{\mathrm{TM}}$. In this case, $f_{\delta}$ is the interpolated wind speed ratio down to canyon top. Once calculated, the sub-resistances $r_{\text {inert }}$ and $r_{\text {int }}$ have to be dimensionalized by the canyon width dimension $W$ (for values per planar area).

Let 1 stand for the upstream wall, 2 for the fraction of road affected by recirculation, 3 for the fraction of road affected by ventilation and 4 for downstream wall. The bulk resistance for the canyon tile is formulated as:

$$
\begin{aligned}
r_{\text {bulk }, \mathrm{c}}{ }^{-1}= & \underbrace{\left(\frac{r_{\text {int }, 1} r_{\text {int }, 2}}{r_{\text {int }, 1}+r_{\text {int }, 2}}+r_{\text {inert,recirc }}\right)^{-1}}_{\left(r_{\text {recirc }}\right)^{-1}} \\
& +\underbrace{\left(\frac{r_{\text {int }, 3} r_{\text {int }, 4}}{r_{\text {int }, 3}+r_{\text {int }, 4}}+r_{\text {inert,venti }}\right)^{-1}}_{\left(r_{\text {venti }}\right)^{-1}} .
\end{aligned}
$$


Note that, in the case of the skimming flow regime, when the contribution of the ventilated region is minor, in order to take into account the transfer of heat from the downstream wall, Eq. (A11) is modified so as to accommodate the downstream wall transfer in $r_{\text {recirc }}$. For the roof tile, the resistance network simplifies into an internal resistance $r_{\text {int,f }}$, put in series with the inertial sublayer resistance $r_{\text {inert,f }}$ :

$$
r_{\text {bulk,f }}=r_{\text {int,f }}+r_{\text {inert,f }} .
$$

\section{References}

Aida M, Gotoh K. 1982. Urban albedo as a function of the urban structure A two-dimensional numerical simulation (Part II). Boundary-Layer Meteorol. 23: 415-424.

Baklanov A, Hänninen O, Slørdal LH, Kukkonen J, Bjergene N, Fay B, Finardi S, Hoe SC, Jantunen M, Karppinen A, Rasmussen A Skouloudis A, Sokhi RS, Sørensen JH, Ødegaard V. 2006. Integrated systems for forecasting urban meteorology, air pollution and population exposure. Atmos. Chem. Phys. 7: 855-874.

Baklanov A, Grimmond CSB, Mahura A, Athanassiadou M. 2008. 'Enhancing mesoscale meteorological modelling capabilities for air pollution and dispersion applications'. Annex to Join Report of COST Action 728 and GURME Overview of Existing Integrated (off-line and on-line) Mesoscale Meteorological and Chemical Transport Modelling Systems in Europe. WMO: Geneva. http://www.cost728.org/Publications.htm.

Barlow JF, Belcher SE. 2002. A windtunnel model for quantifying fluxes in the urban boundary-layer. Boundary-Layer Meteorol. 104: 131-150.

Barlow JF, Harman IN, Belcher SE. 2004. Scalar fluxes from urban street canyons. Part I: Laboratory simulation. Boundary-Layer Meteorol. 113: 369-385.

Best MJ. 2005. Representing urban areas within operational numerical weather prediction models. Boundary-Layer Meteorol. 114: 91-109.

Best MJ. 2006. Progress towards better weather forecasts for city dwellers: from short range to climate change. Theor. Appl. Climatol. 84: 47-55.

Best MJ, Beljaars A, Polcher J, Viterbo P. 2004. A proposed structure for coupling tiled surfaces with the planetary boundary layer. J. Hydrometeorol. 5: 1271-1278.

Best MJ, Grimmond CSB, Villani MG. 2006. Evaluation of the urban tile in MOSES using surface energy balance observations. Boundary-Laye Meteorol. 118: 503-525.

Blackadar AK. 1979. High-resolution models of the planetary boundary layer. In: Advances in Environmental Science and Engineering, Pfafflin J Ziegler E (eds.) 1, $\mathrm{N}^{\circ}$ 1, Gordon and Breach.

Clark PA, Best MJ, Porson A. 2008. 'Evolution of urban surface exchange in the UK Met Office's Unified Model'. Chapter 3.2 in Urbanization of Meteorological and Air Quality Models. Final report for COST action 728. http://www.cost728.org/Publications.htm.

Cox PM, Betts RA, Bunton CB, Essery RLH, Rowntree PR, Smith J. 1999. The impact of the new land surface physics on the GCM simulation of climate and climate sensitivity. Clim. Dyn. 15: 183-203.

Dupont S, Mestayer PG. 2006. Parameterization of the urban energy budget with the Submesoscale Soil Model. J. Appl. Meteorol. Climatol. 49: $1744-1765$.

Essery R, Best MJ, Cox PM. 2001. 'MOSES 2.2 Technical Documentation'. Hadley Centre Technical Report No 30. Met Office: Exeter, UK.

Essery R, Best MJ, Betts RA, Cox PM. 2003. Explicit representation of subgrid heterogeneity in a GCM land surface scheme. J. Hydrometeorol. 4: $530-543$.

Fisher B, Joffre S, Kukkonen J, Piringer M, Rotach M, Schatzmann M. (eds.) 2006. Meteorology applied to urban air pollution problems. Final report COST action 715 . http://www2 dmu.dk/atmosphericenvironment/cost/FinalReports715.htm.

Garratt JR. 1994. The atmospheric boundary layer. Cambridge Atmospheric and Space Science Series. Cambridge University Press: Cambridge, UK.

Grimmond CSB, Oke TR. 1999. Aerodynamic properties of urban areas derived from analysis of surface form. J. Appl. Meteorol. 38: $1262-1292$.

Grimmond CSB, Blackett M, Best M, Barlow J, Baik JJ, Belcher S, Bohnenstengel SI, Calmet I, Chen F, Dandou A, Fortuniak K, Gouvea ML, Hamdi R, Hendry M, Kawai T, Kawamoto Y, Kondo H, Krayenhoff ES, Lee SH, Loridan T, Martilli A, Masson V, Miao S, Oleson K, Pigeon G, Porson A, Ryu YH, Salamanca F, Steeneveld GJ,
Tombrou M, Voogt J, Young D, Zhang N. 2010. The International Urban Energy Balance Models Comparison Project: First results from Phase 1. J. Appl. Meteorol. Climatol. DOI: 10.1175/2010JAMC2354.1.

Hamdi R, Masson V. 2008. Inclusion of a drag approach in the town energy balance (TEB) scheme: Offline $1 \mathrm{D}$ evaluation in a street canyon. J. Appl. Meteorol. Climatol. 47: 2627-2644.

Harman IN, Best MJ, Belcher SE. 2004a. Radiative exchange in an urban street canyon. Boundary-Layer Meteorol. 110: 301-316.

Harman IN, Barlow JF, Belcher SE. 2004b. Scalar fluxes from urban street canyons. Part II: Model. Boundary-Layer Meteorol. 113: 387-410.

Harman IN, Belcher SE. 2006. The surface energy balance and boundarylayer over urban areas. Q. J. R. Meteorol. Soc. 132: 2749-768.

Jin M, Dickinson RE, Zhang D-L. 2005. The footprint of urban areas on global climate as characterized by MODIS. J. Climate 18: 1551-1565.

Jones AR, Thomson DJ, Hort MC, Devenish BJ. 2006. The UK Met Office's next-generation atmospheric dispersion model, NAME III. In Air Pollution Modelling and its Application XVII. Borrego C, Norman AL. (eds.) Springer Verlag: Berlin.

Kondo A, Ueno M, Kaga A, Yamaguchi K. 2001. The influence of urban canopy configuration on urban albedo. Boundary-Layer Meteorol. 100: 225-242.

Kanda M, Kawai T, Kanega M, Moriwaki R, Narita K, Hagishima A. 2005. A simple energy balance model for regular building arrays. Boundary-Layer Meteorol. 116: 423-443.

Kusaka H, Kondo H, Kikegawa Y, Kimura F. 2001. A simple singlelayer urban canopy model for atmospheric models: Comparison with multi-layer and slab models. Boundary-Layer Meteorol. 101: 329-358. Lee S-H, Park S-U. 2008. A vegetated urban canopy model for meteorological and environmental modelling. Boundary-Layer Meteorol. 126: 73-102.

Lemonsu A, Grimmond CSB, Masson V. 2004. Modeling the surface energy balance of the core of an old Mediterranean city: Marseille. J. Appl. Meteorol. 43: 312-327.

Lock AP, Brown AR, Bush MR, Martin GM, Smith RNB. 2000. A new boundary-layer mixing scheme. Part I: Scheme description and single-column model tests. Mon. Weather Rev. 128: 3187-3199.

Macdonald RW, Griffiths RF, Hall D. 1998. An improved method for the estimation of surface roughness of obstacle arrays. Atmos. Env. 32: 1857-1864.

Martilli A, Clappier A, Rotach MW. 2002. An urban surface exchange parameterization. Boundary-Layer Meteorol. 104: 261-304.

Mason PJ. 1988. The formation of areally averaged roughness lengths. Q. J. R Meteorol. Soc. 114: 399-420.

Masson V. 2000. A physically based scheme for the urban energy budget in atmospheric models. Boundary-Layer Meteorol. 94: 357-397.

Masson V, Grimmond CSB, Oke TR. 2002. Evaluation of the Town Energy Balance (TEB) scheme with direct measurements from dry districts in two cities. J. Appl. Meteorol. 11: 1011-1026.

McCabe A, Brown AR. 2007. The role of surface heterogeneity in modelling the stable boundary layer. Boundary-Layer Meteorol. 122: 517-534.

Nunez M, Oke TR. 1977. The energy balance of an urban canyon. J. Appl. Meteorol. 16: 11-19.

Oke TR. 1987. Boundary-Layer Climates. Methuen: London.

Porson A, Clark PA, Harman IN, Best MJ, Belcher SE. 2010. Implementation of a new urban energy budget scheme in the MetUM. Part II: Validation against observations and model intercomparison. Q. J. R. Meteorol. Soc. 136: 1530-1542, DOI: 10.1002/qj.572.

Porson A, Harman IN, Belcher SE. 2009. How many facets are needed to represent the surface energy balance of an urban area? Boundary-Layer Meteorol. 132: 107-128.

Sparrow EM, Cess RD. 1970. Radiation Heat Transfer. Chaps. 3-4, appendices A and B, 75-136 and 300-313. Thermal Science Series, Brooks/Cole: Belmont, California.

Voogt JA, Grimmond CSB. 2000. Modeling surface sensible heat flux using surface radiative temperatures in a simple urban area. J. Appl. Meteorol. 39: 1679-1699.

Warrilow DA, Sangster AB, Slingo A. 1986. 'Modelling of land surface processes and their influence on European climate'. Dynamical Climatology Tech. Note 38. Met Office: Exeter, UK.

Yee SYK. 1988. The force-restore method revisited. Boundary-Layer Meteorol. 43: 85-90.

Zilitinkevich SS, Mammarella I, Baklanov AA, Joffre SM. 2008. The effect of stratification on the aerodynamic roughness length and displacement height. Boundary-Layer Meteorol. 129: 179-190. 